WORKING PAPER \# 532

PRINCETON UNIVERSITY

INDUSTRIAL RELATIONS SECTION

AUGUST 2008

http://www.irs.princeton.edu/pubs/pdfs/532.pdf

\title{
Job Search and Unemployment Insurance: New Evidence from Time Use Data
}

\author{
Alan B. Krueger \\ Princeton University and NBER \\ And \\ Andreas Mueller \\ Stockholm University and Princeton University
}

First Draft: July 10, 2008

This Draft: August 26, 2008

* We have benefited from helpful discussions with Larry Katz, Per Krusell, Phil Levine, and Bruce Meyer, and seminar participants at Princeton, the NBER Labor Studies Program and the 2nd Nordic Summer Symposium in Macroeconomics. Alan Krueger was the Leon Levy member of the Institute for Advanced Study at Princeton when the paper was written. Andreas Mueller gratefully acknowledges financial support from the Handelsbanken "es Research Foundations. 


\title{
Job Search and Unemployment Insurance: New Evidence from Time Use Data
}

\begin{abstract}
This paper provides new evidence on job search intensity of the unemployed in the U.S., modeling job search intensity as time allocated to job search activities. The main findings are: 1) the average unemployed worker in the U.S. devotes about 41 minutes to job search on weekdays, which is substantially more than his or her European counterpart; 2) workers who expect to be recalled by their previous employer search substantially less than the average unemployed worker; 3) across the 50 states and D.C., job search is inversely related to the generosity of unemployment benefits, with an elasticity between -1.6 and $-2.2 ; 4)$ the predicted wage is a strong predictor of time devoted to job search, with an elasticity in excess of 2.5 ; 5) job search intensity for those eligible for Unemployment Insurance (UI) increases prior to benefit exhaustion; 6) time devoted to job search is fairly constant regardless of unemployment duration for those who are ineligible for UI. A nonparametric Monte Carlo technique suggests that the relationship between job search effort and the duration of unemployment for a cross-section of job seekers is only slightly biased by length-based sampling.
\end{abstract}

JEL Codes: J64, J65

Key words: unemployment, unemployment insurance, job search, time use, unemployment benefits, inequality

Alan B. Krueger

Woodrow Wilson School

and Economics Department

Princeton University

Princeton, NJ 08540

Andreas Mueller

Institute for International Economic Studies

Stockholm University

SE-106 91 Stockholm

Sweden 


\section{Introduction}

It is well known that since the early 1980s the unemployment rate has been lower in the U.S. than in Europe. Our tabulations of international time use data (circa 19982007) also indicate that unemployed Americans tend to devote much more time to searching for a new job than their European counterparts (see Figure 1). On weekdays, for example, the average unemployed worker spent 41 minutes a day searching for a job in the U.S., compared with just 12 minutes in the average European country with available data. One explanation for the comparatively low unemployment rate and high search time in the U.S. is the relatively modest level and short duration of Unemployment Insurance (UI) benefits in most states. In this paper we examine the effects of UI on the amount of time devoted to job search by unemployed workers in the U.S., using features of state UI laws for identification.

A large and related literature examines the effects of UI on the duration of unemployment spells. For example, more generous UI benefits have been found to be associated with longer spells of unemployment, with an elasticity of about 1.0 (see Krueger and Meyer (2002) for a survey). In addition, the job finding rate jumps up around the time benefits are exhausted (Moffitt, 1985, Katz and Meyer, 1990a; see Card, Chetty and Weber, 2007 for a critical review). UI is expected to affect the duration of unemployment through its effect on the amount of effort devoted to searching for a job and the reservation wage of the unemployed, yet these variables have rarely been studied directly. ${ }^{1}$ We attempt to fill this void by modeling the amount of time that unemployed

\footnotetext{
${ }^{1}$ See Feldstein and Poterba (1984) and Jones (1988) for evidence on self-reported reservation wages and unemployment in the U.S. and Great Britain.
} 
individuals devote to searching for a new job over the course of unemployment spells using data from the American Time Use Surveys (ATUS) from 2003 to 2007.

Section 2 summarizes theoretical predictions concerning search time by the unemployed, starting with Mortensen's (1977) canonical model of UI and job search. Search effort is typically modeled in terms of time, as the opportunity cost of search time is foregone leisure (ignoring hedonic costs of job search). Search time and the reservation wage are the choice variables that determine the duration of unemployment in search models. Mortensen's model yields clear predictions regarding the effects of the level and duration of UI benefits on search intensity for UI eligible and ineligible job seekers. We calibrate the Mortensen model and solve it numerically to illustrate the effect of the wage offer distribution (mean and variance) on time devoted to job search effort. The amount of time devoted to job search each week is expected to increase as UI benefits approach their exhaustion point, and if the mean or variance of the wage offer distribution increases; search time is expected to decrease if level or maximum duration of UI benefits increases, and workers expecting to be recalled should search less. We empirically test these predictions.

Section 3 describes the ATUS data and presents summary statistics. Following the theoretical literature, we model the amount of time devoted to job search. In Section 4 we estimate the effect on job search of the generosity of UI benefits, job seekers' predicted wages, within-state residual wage dispersion, recall expectations and other variables. Most importantly, we find that job search intensity is inversely related to UI benefit generosity for those who are eligible for UI, consistent with search theory. Section 5 compares the profile of job search activity by duration of unemployment for those eligible or ineligible for UI. We find a striking contrast in the profiles of job search 
activity across those with different durations of unemployment: search activity increases as week 26 (benefit exhaustion) approaches for the UI eligible, while the profile is fairly flat for those who are ineligible for UI. One econometric issue, however, is that that the composition of the sample changes over the duration of unemployment spells, as those who search successfully and find a job exit the sample. To consider the importance of this issue for the job search profiles, section 5 also provides a simulation of the effect of bias due to length-based sampling on the job search-unemployment profile.

Section 6 considers the further information that would be required to use our estimates to design the optimal UI policy. Section 7 offers some concluding thoughts as to how our results relate to search theory and how time-use data can be used to further study UI and job search behavior.

\section{Theoretical considerations}

Mortensen presents a search model with variable search effort and analyzes the effects of UI on search effort and, more generally, the escape rate from unemployment. In this model, an individual has two choice variables, search effort, $\mathrm{s}_{\mathrm{t}}$, and the reservation wage, $\mathrm{w}_{\mathrm{t}}$. Search effort is modeled as time allocated to job search, as the opportunity cost of search is foregone leisure. Given search effort, the arrival rate of job offers is constant $\left(\alpha s_{t}\right)$ and the wage is drawn from a known distribution $\mathrm{F}(\mathrm{w})$ with upper bound $\bar{w}$. The value function of an unemployed individual who is eligible for UI benefits is:

$$
V(t, b)=\frac{1}{1+r h} \max _{0 \leq s_{t} \leq 1, w_{t} \geq 0}\left[h u\left(b, 1-s_{t}\right)+V(t-h, b)+\alpha s_{t} h \int_{w_{t}}^{\bar{w}}[U(x)-V(t-h, b)] d F(x)\right]
$$


where $t$ is time until benefit exhaustion, $h$ the length of each period, $u()$ the flow utility for the period, $b$ the unemployment benefit, and $U(w)$ is the value of a job with wage w. There is no saving, so consumption equals the wage.

The first order conditions are:

$$
\begin{aligned}
& \left(s_{t}\right): u_{2}\left(b, 1-s_{t}\right)=\alpha \int_{w_{t}}^{\bar{w}}[U(x)-V(t-h, b)] d F(x) \\
& \left(w_{t}\right): U\left(w_{t}\right)=V(t-h, b)
\end{aligned}
$$

The optimal choice of how much time to spend searching trades off the marginal cost of foregone leisure against the increase in the probability of obtaining a job offer (times the expected gain from such an offer), and the optimal reservation wage strategy is to accept any wage offer that yields a value greater than or equal to the value of remaining unemployed at the end of the period.

The Mortensen model predicts that for a newly laid-off worker, search effort is decreasing in the maximum benefit duration $\mathrm{T}$ and in the benefit level $\mathrm{b} .^{2}$ Job search effort is predicted to increase over the unemployment spell as benefits are exhausted. After benefits are exhausted ( $\mathrm{t}=\mathrm{T})$, job search effort is predicted to remain constant. If leisure and consumption are complements, search effort jumps up at the moment of benefit exhaustion; if they are substitutes search effort jumps down (see Mortensen, 1977). Figure $2 \mathrm{a}$ illustrates the effect of benefit generosity on job search over the spell of unemployment for a worker initially eligible for 6 months of UI benefits. ${ }^{3}$

For those unemployed who are not eligible for UI or who have exhausted their UI benefits, search effort is increasing in the benefit level. This implication is called the

\footnotetext{
${ }^{2}$ The latter prediction requires the plausible assumption that consumption and leisure are complements.

${ }^{3}$ Figures $2 \mathrm{a}-2 \mathrm{~d}$ draw the case where the marginal utility of leisure is independent of consumption (i.e. if $\left.\mathrm{u}_{12}()=0.\right)$.
} 
entitlement effect, as higher benefits raise the value of being unemployed in the future and thus raise the value of obtaining a job. ${ }^{4}$ An unemployed individual who is ineligible for benefits is predicted to devote a constant amount of time to job search because of the absence of learning and assumption of stationarity in the Mortensen model. ${ }^{5}$ Figure $2 b$ contrasts the search time profile of eligible and ineligible workers. In actuality, the profile for the UI ineligible can lie above or below that of the UI eligible, depending on how their personal characteristics affect their wage offer distributions, but the profile should be flat for the ineligible over the spell of unemployment in Mortensen's model.

Finally, to analyze the predictions of the model with respect to the wage offer distribution, we solve the model numerically, assuming a log normal distribution of wages. ${ }^{6}$ An increase in the mean wage offer increases the value of all potential jobs and thus increases the return to search. This is illustrated in Figure 2c. Figure 2d shows that a higher dispersion of potential wage offers, holding the average log wage offer constant, also leads to higher search effort. The intuition for this result is that, with a higher dispersion of potential wages, there is a greater benefit from searching for a high paying job, whereas if wage offers are compressed the individual might as well accept the first job offered, as the next is not likely to be much better. ${ }^{7}$ Note, however, that this conclusion depends on the curvature of the utility function: if workers are extremely risk

\footnotetext{
${ }^{4}$ See Levine (1993) for some evidence on the entitlement effect.

${ }^{5}$ This result also relies on the assumption of constant worker productivity over a spell of unemployment. See, for example, Ljungqvist and Sargent (1998) for a search model with skill depreciation.

${ }^{6}$ Figures $2 \mathrm{a}-2 \mathrm{~d}$ are computed for $\mathrm{u}(\mathrm{C}, \mathrm{L})=\log (\mathrm{C})-\gamma(1-\mathrm{L})^{2}$, which satisfies the standard assumptions $\mathrm{u}_{1}, \mathrm{u}_{2}$ $>0$ and $\mathrm{u}_{11}, \mathrm{u}_{22}<0$. Note that this formulation of the utility function in leisure $\mathrm{L}$ is equivalent to a quadratic search cost for the unemployed. We do not allow for on-the-job search (though introducing on-the-job search would leave the results qualitatively unchanged). Potential wage offers are assumed to be lognormally distributed (approximated with a discrete distribution of 100 points).

${ }^{7}$ See Stigler (1962) for a seminal discussion of how wage dispersion affects the payoff from search effort.
} 
averse, a greater mean-preserving spread in wages might actually lower the expected utility gain of getting a job and thus also the time allocated to job search.

\section{Extensions}

Katz (1986) extends the standard search model to allow for the possibility of recall to the previous job. ${ }^{8}$ He shows that in a model with binary choice of search and probability $\mathrm{p}$ of recall, the unemployed decide not to search if the probability of recall is above a certain threshold. Therefore, we expect that the unemployed with an expectation of recall to search less on average., 9,10

The tax system also has an impact on job search through the after-tax wage offer distribution. Ljungqvist and Sargent (1995) provide a calibrated model in which progressive taxation reduces job search effort. The reason is that progressive taxation leads to after-tax wage compression, lowering the value of searching for a high paying job and thus reducing search effort.

Allowing for saving, borrowing and liquidity constraints will alter Mortensen's prediction of a flat job search profile over time for those who are ineligible for benefits. In such a model, search intensity would be expected to rise over time as individuals spend down their wealth and borrow at rising interest rates. Nonetheless, eligible UI recipients would still be expected to have a search profile that rises faster than that of ineligible job seekers until benefits are exhausted.

\footnotetext{
${ }^{8}$ See, also, Feldstein (1976).

${ }^{9}$ Such an observation would also be consistent with Alvarez and Shimer (2008), who make a distinction between search and rest unemployment. Rest unemployment is defined as a state where an unemployed worker does not search and waits for local labor market conditions to improve.

${ }^{10}$ See also the empirical work of Katz and Meyer (1990a,b) on recall and job finding hazards.
} 
Stock-flow matching models of the labor market have a different implication for the profile of job search by unemployment duration. In this class of models, job search is high in the first weeks of an unemployment spell when the unemployed worker screens the stock of existing vacancies, but drops thereafter once the entire stock is explored (and rises again as the time of benefit exhaustion approaches). See, for example, Coles and Smith (1998) for an empirical analysis of such a model.

\section{Data and Descriptive Statistics}

We use data from five consecutive years (2003-07) of the ATUS, which is sponsored by the Bureau of Labor Statistics (BLS) and conducted by the U.S. Census Bureau. The ATUS is a nationally representative time-use survey, which covers the whole civilian non-institutional population of age 15 and older. The sample is drawn from the $8^{\text {th }}$ outgoing rotation group of the Current Population Survey (CPS). Respondents are interviewed within 2-5 months of their last CPS interview. The ATUS collects detailed information on the amount of time respondents devoted to various activities in the previous day. Job search activities include contacting a potential employer, calling or visiting an employment agency, reading and replying to job advertisements, job interviewing, etc. The Appendix Table provides a detailed list of activities that are identified as job search.

We restrict our sample to the population of age 20-65 to abstract from issues related to youth unemployment and retirement. The ATUS labor force recode defines unemployment in the same way as the CPS (not working in the reference week, actively looking for a job in the 4 weeks prior to the interview, and available for work in the 
reference week). ${ }^{11}$ The CPS/ATUS definition of unemployed also includes those on temporary layoff with an expectation of recall to their previous employer, regardless of whether they looked for work in the four weeks prior to the survey. Our sample consists of 2,171 unemployed individuals (of which 344 on temporary layoff), 42,934 employed individuals, and 11,091 people who are classified as out of the labor force. Sample weights are used in all of our estimates. The sample unemployment rate is $5.2 \%$, which exactly matches the official unemployment rate over the same period.

We can disaggregate the unemployed into four groups: job losers, those expecting to be recalled to their previous employer, voluntary job leavers, and re-/new entrants into the labor force. The ATUS questionnaire, however, only contains a question on whether the unemployed expect to be recalled. Thus, we use information from the final CPS interview to classify individuals into the other three groups. Information on type of unemployment from the CPS was used to classify those who were already unemployed at the time of their last CPS interview. Those who became unemployed between the CPS and ATUS interview were classified either as a job loser (if they were employed in the CPS) or re-/new entrant (if they were out of the labor force in the CPS). Specifically:

- Job losers are defined as those on layoff in the CPS, those who report in the CPS that their temporary job has ended and those who are employed at the time of the CPS interview (and subsequently became unemployed). Those with an expectation of recall to their previous employer at the time of the ATUS interview are excluded from this category.

\footnotetext{
${ }^{11}$ Note, however, that the reference week is defined as the 7 days prior to the interview (including the diary day), as opposed to the week prior to the interview as in the CPS.
} 
- Unemployed on temporary layoff with an expectation of recall are defined as those who indicate (in the ATUS interview) that they were given a date to return to work or that they expect to be recalled to their previous employer within the next 6 months.

- Re- or new entrants are defined as those unemployed who indicate that they were reor new entrants in the CPS. Those who are classified as out of the labor force in the CPS but as unemployed in the ATUS are also included in this category.

- Voluntary job leavers are defined as those who indicate that they quit their job. Note that we were able to identify voluntary job leavers only when they were already unemployed at the time of the CPS interview.

The Mortensen model has different predictions based on UI eligibility. Because the ATUS lacks information on UI receipt, we infer UI eligibility from the type of unemployment and the workers' full-time/part-time status on the previous job. We classify job losers and those on temporary layoff as eligible for UI, and re-entrants, new entrants and voluntary job leavers as ineligible. In states where those seeking part-time jobs do not qualify for UI, we classify those who previously worked part-time as ineligible.

There is some question as to whether self-reported voluntary job leavers actually receive benefits. Gruber (1994) reports that over $20 \%$ of self-reported job leavers collected UI benefits. Moreover, Gruber finds that the quitters behave similarly (in terms of the consumption response to UI) as those eligible for benefits. 


\section{Descriptive statistics of job search activities}

Table 1a reports descriptive statistics on the average number of minutes devoted to job search by labor force status. It also shows the participation rate in job search, defined as the fraction of those with nonzero search time on the diary day. Several results are worth highlighting. First, the unemployed spend around 32 minutes a day (including weekends) searching for a job, whereas the employed and those classified as out of the labor force devote less than a minute a day to job search, on average. ${ }^{12}$ Even if we restrict the sample to those who were classified as unemployed in the CPS interview (2-5 months prior to the ATUS interview), those classified as out of the labor force in ATUS searched for only 4.2 minutes. This suggests that the conventional labor force categories represent meaningfully different states. ${ }^{13}$

Second, job search is heavily concentrated on weekdays (see Table 1b). Nearly a quarter of the unemployed engage in job search activities on any given weekday, compared with $6.7 \%$ on weekends. Also, on an average weekday, the unemployed search around 41 minutes for a job compared with 9 minutes on an average weekend day. Third, those who participate in job search on the diary day tend to devote a great deal of time to it. Figure 3 shows a kernel density diagram for the duration of job search conditional on searching on the diary day. The average duration of job search among those who searched is 167 minutes, and a quarter of job searchers spent more than 240 minutes searching for a job on the diary day. Fourth, there are large differences in job search effort depending on the reason for unemployment. Job losers search 32 minutes more (or 3.4 times as much) than those who expect to be recalled to their previous job, and around 22 minutes

\footnotetext{
${ }^{12}$ In a companion paper (Krueger and Mueller, 2008) we found similar evidence across 14 countries.

${ }^{13}$ Corroborating evidence from job finding rates is in Flinn and Heckman (1983); see Jones and Riddell (1999) for conflicting evidence for Canada.
} 
more (or twice as much) than re- or new entrants. Job leavers also have a high intensity of search, devoting almost an hour to job search a day, on average. Finally, we report average minutes of job search by UI eligibility status. Those eligible for UI search 13 minutes more on an average day than those who are not eligible. This difference, however, falls to 6 minutes when we control for observable characteristics such as age, education, sex, marital status, and a dummy for the presence of children. Those eligible for UI are generally older, more highly educated, and are more likely to be male as well as married (or cohabiting).

\section{Unemployment Insurance}

To qualify for unemployment benefits all states require a worker to have earned a certain amount of earnings during a reference period or to have worked for a certain period of time. The replacement rate is typically around $50 \%$ to $60 \%$ of the wage earned on the previous job, subject to a maximum benefit. The maximum weekly benefit varies widely across states, ranging from $\$ 210$ in Mississippi to $\$ 575$ in Massachusetts in 2007. ${ }^{14}$ Ten states provide dependents allowances beyond the maximum benefit. ${ }^{15}$

In most states, the maximum duration of benefits is 26 weeks, although there are some exceptions: Massachusetts (30 weeks), Montana (28 weeks) and Washington (30 weeks until 2007). During 2003, UI recipients were able to receive up to 13 additional

\footnotetext{
${ }^{14}$ According to Krueger and Meyer (2002) around 35\% of the unemployed receive the maximum benefit amount.

${ }^{15}$ These states are AK, CT, IA, IL, MA, ME, NM, OH, PA and RI. The number of dependents usually includes children of age 17 and younger, and in some cases the spouse. In Illinois and Maine, the spouse counts as a dependent if not working full-time and, therefore, we count a spouse if he or she is not working or the reported usual hours are less than 35. In Iowa, the spouse counts as a dependent only if his or her weekly gross wage is below $120 \$$, which is about $1 / 6$ of the state average wage, and, in Ohio, if the wage does not exceed $25 \%$ of the claimant's average weekly wage. For this reason, we count the spouse in those two states as a dependent if he or she is not working or reports usual hours of 10 or less. In Connecticut and Pennsylvania, the spouse counts independent of whether he or she is working.
} 
weeks of benefits through the federal Temporary Extended Unemployment Compensation Act of 2002, and benefits were extended for 26 weeks in a small number of "high" unemployment states. In the period 2004-07, however, extended benefit programs were in effect in only a few states and only for limited periods of time (affecting less than $0.5 \%$ of our sample of unemployed). We exclude observations from 2003 when we examine job search behavior around 26 weeks of unemployment for the UI eligible because of complications caused by the extended benefits program.

As described below, our regression model exploits variation in the maximum weekly benefit amounts across states and number of dependents. The data for maximum weekly benefit amounts is taken from the U.S. Department of Labor's Comparison of State UI Laws. ${ }^{16}$ We take the average of maximum weekly benefit amounts across the 5 years of the ATUS. We also take into account dependents' allowances.

\section{Job Search Regressions}

To evaluate the predictions of the models outlined in Section 2, we estimated micro regressions in which the total amount of time allocated to job search on the diary day was the dependent variable and the explanatory variables included the maximum weekly UI benefit, the respondent's predicted wage, a measure of wage dispersion in the state, and personal characteristics. We proceeded in two steps. We first estimated the predicted wage and residual wage dispersion facing each job seeker, and then used these estimates as explanatory variables in the job search equation. Specifically, the regression models we estimated are:

$\log \left(\mathrm{w}_{\text {is }}\right)=\mathrm{a}+\mathrm{b} \mathrm{X}_{\mathrm{i}}+\mathrm{d}_{\mathrm{s}}+\varepsilon_{\text {is }}$

\footnotetext{
${ }^{16}$ See http://workforcesecurity.doleta.gov/unemploy/statelaws.asp\#Statelaw.
} 
$\left.\mathrm{s}_{\text {ist }}=\alpha+\beta_{1} \log \left(\mathrm{wba}_{\text {ist }}\right)+\beta_{2} \log \hat{\left(w_{i s}\right.}\right)+\beta_{3} \operatorname{std}(\text { resid. } w)_{\mathrm{s}}+\gamma_{1} \mathrm{X}_{\mathrm{i}}+\gamma_{2} \mathrm{Z}_{\mathrm{i}}+\mathrm{d}_{\mathrm{t}}+\mu_{\text {ist }}$

where $\mathrm{w}_{\text {is }}$ is the hourly wage of worker $\mathrm{i}$ in state $\mathrm{s}, \mathrm{s}_{\text {ist }}$ is time allocated to job search of individual $\mathrm{i}$ in state $\mathrm{s}$ and time $\mathrm{t}$, $\mathrm{wba}_{\mathrm{ist}}$ is the maximum weekly benefit amount, $\mathrm{X}_{\mathrm{i}}$ is a set of controls such as education and sex, which are included in the wage and job search equations, $Z_{i}$ is a set of controls exclusively included in the search equation, $d_{t}$ a time effect (month and year) and $d_{s}$ a state effect. $Z_{i}$ includes dummies for each group of unemployed workers (job loser, on temporary layoff, job leaver and re-/new entrant), married or cohabiting with a partner, the presence of children under age 18 in the household, interaction terms of partner and children with female, and a dummy for whether the diary day was a weekend. The maximum weekly benefit amount varies with individual characteristics in the states where dependents allowances are provided beyond the maximum weekly benefit of a single earner. Standard errors are robust to correlated residuals within states and heteroskedasticity.

The wage equation was estimated using a sample of 319,813 workers from the CPS outgoing rotation group files for 2004 and 2005. We predicted each ATUS respondent's expected $\log$ wage, denoted $\log \left(w_{i s}\right)$, using the coefficients from the wage regression (4). ${ }^{17}$ We computed the standard deviation of residuals from the wage equation for each state (denoted std(resid. w)) as an indicator of the dispersion in the potential wage offer distribution.

Table 2 reports the results of estimating equation (5) for four separate samples. Column 1 shows the results for the full sample of unemployed individuals aged 20-65.

\footnotetext{
${ }^{17}$ Data for the wage equation are taken from the CEPR version of the CPS outgoing rotation group files, which adjusts for top coding and overtime earnings/tips. We exclude from the sample self-employed and self-incorporated, full-time and part-time students and employed with hourly earnings of less than $\$ 1$ or more than $\$ 200$.
} 
Columns 2-4 report the same regressions for UI eligible and ineligible. In the full sample the coefficient on the $\log$ of the maximum weekly benefit is negative but not statistically significant. The elasticity for the maximum weekly benefit is -1.2 when we restrict the sample to those who appear eligible for UI benefits, are not on temporary layoff, and have been unemployed for 26 weeks or less; this is the only sample for which the coefficient on benefits is statistically significant at the $10 \%$ level. To gauge the magnitude of this elasticity, consider the effect of changing the WBA from the state with the lowest to the highest benefit (for a person without dependents). Time devoted to job search is predicted to decrease by 54 minutes a day.

For those not eligible for benefits the elasticity is positive but not significant. A test of the equality of the benefit coefficients for those eligible and ineligible for UI rejects at the 10 percent level, suggesting a different response to benefit generosity. In column (4) we exclude job leavers from the sample of ineligibles because many of them may, in fact, receive UI benefits. For this sample the benefit coefficient is larger (though still insignificantly different from zero), and the difference between the eligibles and ineligibles is significant at the 5 percent level. Consistent with Gruber, in results not shown here we find that UI benefits are negatively and significantly associated with job search time for the subsample of job leavers, suggesting that many receive UI benefits.

We also estimated Tobit models for the same four samples to account for the mass of workers with 0 minutes of job search on the diary day. Table 3 reports estimated coefficients of the Tobit model as well as an adjustment factor that allows one to compute the marginal effect of each variable. The marginal effect of a Tobit model is $\mathrm{dE}(\mathrm{y} \mid \mathrm{x}) / \mathrm{dx}_{\mathrm{i}}=$ $\beta_{\mathrm{i}} * \Phi(\mathrm{x} \beta / \sigma)$ where $\Phi($.$) is the standard normal cdf and, to make the Tobit estimates$ 
comparable to the linear regression models, we evaluate the adjustment factor at the mean values of $\mathrm{x}(\Phi(\bar{x} \hat{\beta} / \hat{\sigma})) .{ }^{18}$ In the full sample, the coefficient on benefits is positive and not significant at conventional levels. In the subsample of eligible unemployed with spells of 26 weeks or less, the coefficient on benefits is significant at the $5 \%$ level and the implied elasticity is -0.8 . Again, the contrast between the benefit effect for those eligible and ineligible for benefits is statistically significant.

Note that the reported elasticities are all calculated with respect to the legislated maximum weekly benefit amount. To estimate the elasticity of job search with respect to actual UI benefits, we estimated a linear and a Tobit model with the log of the state average weekly benefit in place of the maximum weekly benefit. ${ }^{19} \mathrm{We}$ instrument for the actual average benefit with the log maximum weekly benefit. The maximum weekly benefit is a strong instrument for average benefits: the coefficient on the maximum weekly benefit in the first stage is 0.54 with a t-ratio of 11.3 . Table 4 reports the marginal effects of the log average weekly benefits. Taking the IV estimates from column 2 , the implied elasticity is -2.2 for the linear model and around -1.6 for the Tobit model.

To put these estimates in perspective, we can calculate the differential search time between the U.S. and the European countries shown in Figure 1 that is predicted by the difference in benefit generosity and the benefit coefficients. Based on Krueger and Mueller (2008), benefits are $0.114 \log$ points lower in the U.S. over the first 26 weeks of a spell of unemployment. The IV-Tobit estimate in column 2 of Table 4 therefore implies that job search time would be 9 minutes longer in the U.S., and the Two-Stage

\footnotetext{
${ }^{18}$ Note that the effect of dummy variables is different because of the non-linear nature of the Tobit model.

${ }^{19}$ The state average weekly benefit is defined as benefits paid for total unemployment divided by weeks compensated for total unemployment. We take the average of the state average weekly benefit over the years 2003-07 from http://workforcesecurity.doleta.gov/unemploy/content/data.asp.
} 
Least Squares model predicts that it would be 13 minutes longer. American job seekers search about 29 minutes more per weekday than European job seekers. The lower benefit levels in the U.S. could therefore account for from 30 percent to 43 percent of the difference in search time. Although there are some obvious limitations of this calculation - such as the fact that we were not able to restrict the European sample to UI recipients the results suggest that UI benefit generosity can potentially explain a nontrivial share of the difference in search behavior of the unemployed in the U.S. and Europe.

The results in Tables 2 and 3 also show that unemployed workers with an expectation of recall search significantly less than job losers, consistent with Katz's (1986) prediction. Indeed, other things equal, those with an expectation of recall hardly search at all.

The fitted wage is a strong predictor of job search. In the full sample the coefficient is significant at the $5 \%$ level in the linear model and at the $1 \%$ level in the Tobit model. The point estimate of the elasticity at the mean is 3.4 in the linear model and 2.6 in the Tobit model. The estimate from the linear model implies that moving from the state with the lowest to the highest average log wage is associated with a 46 minute increase in time devoted to job search. Note that we control for all the variables of the wage equation (age, sex and education) in the search models in Tables 2 and 3, except for state dummies. If we exclude these variables from the search regressions, the elasticity of the wage is much lower (around 1), which suggests that inter-state wage differentials are a much stronger determinant of time allocated to job search than are wage differences associated with personal characteristics.

The residual wage dispersion term is insignificant but usually positive in most of the OLS and Tobit models. This is a contrast to Krueger and Mueller's (2008) cross- 
country study, which found that job search is higher in countries with higher wage dispersion, controlling for benefits and other factors. One reason might be that residual wage dispersion is lower across the U.S. states than across countries, and therefore conveys less signal than in the cross-country data. The standard deviation of the 90-10 wage ratio is 0.41 in our CPS sample compared with 0.81 in our cross-country sample. It is also worth noting that if we measure wage dispersion by the standard deviation of the exponential of the residual from equation (4), the coefficient on wage dispersion is positive and statistically significant (t-ratio of 1.90) in the full sample. Thus, the empirical effect of wage variability on search intensity is sensitive to functional form.

In results not presented here, we tested the robustness of the findings in Tables 2 and 3 by including the state-level unemployment rate, which had a negative coefficient but was not statistically significant. ${ }^{20}$ If we add an interaction between the unemployment rate and the log weekly benefit, however, we find that the main effect of the unemployment rate becomes negative and significant at the 10 percent level, while the interaction is positive and also significant at the 10 percent level. Because of concern about simultaneous causation - a high unemployment rate could cause fewer people to search for a job and could be caused by low job search intensity - we excluded the unemployment rate and its interaction with benefits from the models in Tables 2 and 3 . We also excluded the duration of unemployment because it is endogenously determined with search time. It is nonetheless reassuring that none of the variables of interest had a qualitatively different effect if these variables were included.

Overall, the regression results provide support for Mortensen's (1977) model to varying degrees. Differences across states in the level of benefits have a negative

\footnotetext{
${ }^{20}$ See Shimer (2004) for an analysis of how search intensity varies with the business cycle.
} 
relationship with job search in the subsample of UI eligible job seekers with unemployment duration of 26 weeks or less. Also, for the UI ineligible, the effect of benefits on job search is predicted to be positive (the entitlement effect). The coefficient has the expected sign but is not significant. However, we can reject at the $10 \%$ level the null hypothesis that the coefficient on maximum weekly benefits is equal for the UI eligible and ineligible (i.e., contrasting the coefficients on benefits in columns 2 and 3 in Table 2 or 3). Finally, our results suggest that a job seeker's predicted wage and recall expectation have strong effects on job search activity, but we find mixed results for residual wage dispersion, probably due to lower variability across states.

\section{Job Search and Unemployment Spell Duration}

The standard search model makes strong predictions regarding the amount of time spent searching for a job by duration of unemployment. In particular, for those eligible for benefits, job search intensity should increase as benefits approach the exhaustion date. By contrast, search intensity by the ineligible should remain constant throughout the unemployment spell. Although it would be preferable to examine these relationships with longitudinal data that track search intensity for the same individuals over the course of their unemployment spells, we can use ATUS data to examine the cross-sectional patterns of job search across those with different durations of unemployment at the time of the survey.

To nonparametrically estimate the unemployment duration-job search profile we utilize LOWESS to plot the fitted values of a locally weighted regression of minutes 
spent in job search on unemployment duration at the time of the ATUS. ${ }^{21}$ We exclude those who have an expectation of recall to their previous employer, as their search behavior is different and affected by the recall strategy of the employer.

Unfortunately, the ATUS interview does not collect information on unemployment duration. Consequently, we derive unemployment duration by taking the unemployment duration reported in the last CPS interview and adding the number of weeks that elapsed between the CPS interview and the ATUS interview. Eighty-six percent of the ATUS interviews were conducted within 3 months of the last CPS interview. For those who were not unemployed at the time of the CPS interview, we impute duration of unemployment by taking half the number of weeks between the CPS and the ATUS interviews. We do not show the weekly LOWESS plot for 13 weeks or less, but simply report the average time allocated to search, as the imputed unemployment duration are quite noisy for those who become unemployed after their last CPS interview. $^{22}$

Figure 4 shows the LOWESS plot separately for those eligible and ineligible for UI benefits. ${ }^{23}$ The unemployment duration-search profile for the UI ineligible group is fairly flat, consistent with standard search models. For the UI eligible, however, job

\footnotetext{
${ }^{21}$ More precisely, LOWESS carries out a linear weighted regression for each week of unemployment duration including the nearest neighbor subset of observations, where weights decline with the distance to the center of the regression. This subset is of size 0.1 (the bandwidth) times the size of the sample.

Note that STATA does not allow the use of survey weights for LOWESS. For this reason, we duplicate each observation $\mathrm{x}$ number of times where $\mathrm{x}$ corresponds to the survey weight (with the "expand" command in STATA). This generates a dataset representative of the population and we carry out our LOWESS in this expanded version of the dataset.

${ }^{22}$ About one third of our sample of unemployed individuals (excluding those on temporary layoff) has an unemployment duration of 14 weeks or more.

${ }^{23}$ Note that we exclude observations on eligible individuals from 2003 because the federal extended benefits program was in effect that year.
} 
search increases sharply between week 15 and 26 of unemployment, from less than 20 minutes to greater than 70 minutes, and then falls back to around 25 minutes.

We probed the robustness of the profiles in Figure 4 by removing the effects of age, sex, and other characteristics (i.e., the explanatory variables in column 1 of Table 2), and then used the residuals in the LOWESS analysis. Figure 5 provides LOWESS plots of the residuals. The general patterns in the duration-search profiles are fairly similar to those in Figure 4, although the increase in time devoted to job search between week 15 and 26 for the UI eligible sample is somewhat smaller after removing the effects of the explanatory variables.

The increase in job search in the weeks prior to benefit exhaustion for the UI eligible sample and the fairly constant amount of time devoted to job search for the UI ineligible are both consistent with Mortensen's (1977) search model. However, the decline in job search after week 26 is unexpected, as the model predicts that workers allocate a constant amount of time to job search after benefits are exhausted. We next explore one possible explanation for the decline in search activity after week 26.

\subsection{Possible Bias Due to Length-Based Sampling}

There is a potential selection issue due to unobserved heterogeneity in the propensity to search for a job: job seekers who devote a lot of effort to searching for a job are more likely to find one and exit the sample, whereas those with a low proclivity to search remain in the sample. This creates a possible "length-based sampling" bias that would tend to cause the search profiles to slope down with unemployment duration. (Notice, however, that the bias could go in the opposite direction if people who search very little become discouraged and leave the labor force.) 
The fact that the relationship between spell duration and job search is fairly flat profile for the UI ineligible sample is an indication that bias due to length-based sampling is probably small, as this group would also be subject to length-based sample bias if workers have heterogeneous commitments to job search. To quantitatively assess the potential bias from length-based sampling, we performed nonparametric Monte Carlo simulations of selection out of unemployment. These calculations are meant to be illustrative. To proceed, we estimated a job search "production function" of the following form:

$P_{i}=a+b^{*} S_{i}$

where $\mathrm{P}_{\mathrm{i}}$ is the probability of transitioning from unemployment to work in a given week for individual $\mathrm{i}$ and $\mathrm{S}_{\mathrm{i}}$ is the time allocated to job search. As explained below, we estimate 'b' from the National Longitudinal Survey of Youth (NLSY79). We obtain the intercept 'a' by matching the fraction of survivors in week 39 in our simulations to the fraction of survivors in week 39 in ATUS (around 32\%).

Given estimates of ' $a$ ' and ' $b$ ', we start with the pool of unemployed individuals in ATUS with a short duration of unemployment, defined as less than 13 weeks, as the base group for our simulation. These individuals can be thought of as virtually unaffected by length-based sampling because they have had relatively little time to exit the sample. We assume that each job seeker's daily job search time is fixed (i.e., the same as in this initial period regardless of how many weeks they subsequently search for a job) to exclusively reflect the effect of individual heterogeneity. Our goal is to simulate the relationship between job search time and the duration of unemployment from week 13 to week 39 that can be attributed solely to length-based sampling. We use the job finding production function and initial search times to simulate the job finding rate each week 
and the average search time for those who remain unemployed each week. The profile that emerges is purely the result of length-based sampling under these assumptions.

More specifically, we use the following algorithm:

1. Set $d=13$ for all of the unemployed in our base group, where $d$ represents the number of weeks of unemployment so far.

2. Draw a random number e from the uniform distribution $(0,1)$ for each simulated worker with a spell that has lasted to week d. If $\mathrm{e}<\mathrm{P}_{\mathrm{i}}=\mathrm{a}+\mathrm{b} * \mathrm{~S}_{\mathrm{i}}$, we assume unemployed worker finds a job and exits the sample in that week. If $\mathrm{e}>=\mathrm{P}_{\mathrm{i}}$, the unemployed worker does not find a job and remains unemployed.

3. Reset $d=d+1$ and, for those remaining in the sample, we compute the average search time. Repeat steps (2) and (3) until d=39.

4. Iterate (1)-(4) 50 times and then take the average of the simulated data.

\subsection{Estimation of the linear job search technology}

It is not possible to examine the relationship between the amount of time spent searching for a job and the likelihood of finding a job in the ATUS. Consequently, we use data from the National Longitudinal Survey of Youth 1979 (NLSY79) to estimate the parameter ' $b$ ' in the linear job search technology. ${ }^{24}$ Specifically, we use the 1981 supplemental questions on job search, which asked how much time job searchers spent looking for a job in the seven days prior to the interview and what kind of job search methods they used in their current unemployment spell (e.g., asking friends, placing or answering ads, direct contacts with employers and using state or private employment services). ${ }^{25}$ We restrict the NLSY sample to unemployed individuals age 18-24. The sample size is 1,162 .

\footnotetext{
${ }^{24}$ Holzer (1987) uses the same data set to compare job search of the employed and unemployed.

${ }^{25}$ The reported average search time per week is 238 minutes, or 34 minutes a day, which is similar to our results in the ATUS.
} 
We model the likelihood that an unemployed worker accepts a job with a linear probability model. The dependent variable equals 1 if the unemployed worker has found a job and 0 if she or he has not. We regress this indicator variable on the number of minutes spent searching for a job in the seven days prior to the interview, controlling for age, sex and years of education. As Table 5 reports, the estimated coefficient is small: increasing search by one hour increases the probability of finding a job by 0.31 percentage points. We suspect, however, that our model specification does not capture the full effect of search effort on the probability of finding a job because of the impact of time lags between search effort and job finding. For this reason, we instrument for the number of minutes searched in the last seven days with the total number of job search methods used in the current unemployment spell. Our hope is that this approach captures the full effect of search time on job finding because the number of methods used is more closely associated with past search effort.

Column 3 in Table 5 indicates that the number of job search methods is a strong instrument for minutes of job search. The coefficient is significant at the $1 \%$ level with a t-ratio of 5.59. The results of the second-stage regression indicate that the estimated coefficient on minutes of job search is much larger than in the baseline OLS regression: increasing search by one hour raises the probability of finding a job by 1.83 percentage points. To obtain the slope coefficient ' $b$ ' used in the simulation of length based sampling, we divide this estimate (and the OLS estimate) by seven to adjust for the fact that in ATUS we observe time allocated to job search only on one day of the week.

We can compare our estimates to Paserman (2007) who uses the NLSY79 to estimate how time spent on job search relates to the probability of receiving a job offer for different methods of job search. More precisely, he assumes that the probability of 
receiving a job offer takes the form $\mathrm{P}_{\mathrm{ij}}=1-\left(1+\mathrm{S}_{\mathrm{ij}}\right)^{-\alpha \mathrm{j}}$ where $\mathrm{j}$ is the method of job search used by individual $\mathrm{i}$, and then uses maximum likelihood techniques to estimate $\alpha_{\mathrm{j}}$. To make his estimates comparable to ours, we evaluate the marginal effect of hours spent on job search, $\mathrm{dP}_{\mathrm{j}} / \mathrm{dS}_{\mathrm{j}}=\alpha_{\mathrm{j}}\left(1+\mathrm{S}_{\mathrm{j}}\right)^{-\alpha \mathrm{j}-1}$, at the average $\mathrm{S}_{\mathrm{j}}$. The marginal effects are closer to our OLS estimate than our IV estimate: $\mathrm{dP}_{\mathrm{j}} / \mathrm{dS}_{\mathrm{j}}$ is lowest for "newspaper ads" $(0.54 \%)$ and largest for "other methods" $(1.36 \%){ }^{26}$ The similarity is reassuring and our higher IV estimates are to be expected as we try to account for differences in past job search behavior by instrumenting for time spent searching last week by the number of job search methods used during the entire unemployment spell.

\subsection{Simulation Results}

Figure 6 plots the fraction of survivors by week of unemployment spell. A survivor is defined as an unemployed individual who has not found a job yet. Only $32 \%$ of those unemployed in week 13 "survive" until week 39. This suggests that sample selection could be an important issue. Yet the results in Figure 7 show that despite the large number of those who find a job between week 13 and 39, length based sampling is predicted to impart a relatively minor bias on average search time. The decrease in average search time due to our rather extreme assumptions about the length-basedsampling process is only about 8 minutes between week 13 and 39. If we use the OLS estimate of the effect of search time on job finding instead of the IV estimate the predicted bias is even smaller, only around 1 minute.

\footnotetext{
${ }^{26}$ Note that we use a different dependent variable ("accepted job") than Paserman ("received job offer"). Because job seekers in the NLYS79 accept only around half of the job offers they receive, we divide the marginal effects by two when comparing his estimates to ours.
} 
These simulations are meant to be illustrative, but they suggest the difficulty of explaining the general profiles in Figure 4 with reference to bias due to length-based sampling. Length-based sampling seems particularly unlikely to account for the large drop in average search time after week 26 for the eligible UI sample in Figure 4, or for the run up in search time prior to week 26 , as the bias is likely to be monotonically increasing over spell durations and small.

\section{Moral hazard versus liquidity effects of UI}

What are the implications of our estimates for the optimal unemployment insurance policy? One way to interpret our findings regarding the effects of UI benefit generosity and maximum duration on time devoted to job search is as a "moral hazard" effect: UI indirectly subsidizes leisure while unemployed and thus reduces the incentives to search for a new job and return to work. However, in the presence of borrowing constraints and, more generally, in the absence of insurance markets for unemployment risk, UI also enables job seekers to smooth consumption and thus reduces the pressure for them to rush back to work. Chetty (2008) shows that the effect of a one-period increase in benefits can be decomposed into a liquidity effect and moral hazard effect:

$\mathrm{ds}_{\mathrm{t}} / \mathrm{db}_{\mathrm{t}}=\mathrm{ds}_{\mathrm{t}} / \mathrm{dA}_{\mathrm{t}}-\mathrm{ds}_{\mathrm{t}} / \mathrm{dw}_{\mathrm{t}}$

where $\mathrm{ds}_{\mathrm{t}} / \mathrm{dA}_{\mathrm{t}}$ is the marginal change in search effort in response to a one dollar increase in cash on hand (the liquidity effect) and $\left(-\mathrm{ds}_{\mathrm{t}} / \mathrm{dw}_{\mathrm{t}}\right)$ is the marginal change in search effort in response to a one dollar increase in the wage in period t (the moral hazard effect). He

argues that the optimal level of unemployment benefits depends on the relative 
importance of these two effects. If $\mathrm{ds}_{t} / \mathrm{dA}_{\mathrm{t}}$ is close to zero, agents reveal that they wish not to rush back to work and thus the moral hazard effect prevails, but if $\mathrm{ds}_{t} / \mathrm{dA}_{\mathrm{t}}$ is large, the liquidity effect is important and potentially outweighs the disincentive effect of UI.

To evaluate the importance of liquidity effects we follow Chetty (2008) and split the sample of UI eligible job seekers into those with a working partner (married or unmarried) and those without. Those with access to a secondary income source are more likely to maintain consumption during a spell of unemployment and thus should be less responsive to unemployment benefits. We find support for this hypothesis as the coefficient on benefits for those with a working partner is positive and statistically insignificant whereas the elasticity for those without a working partner is -2.1 and significant at the 5\% level (t-ratio 2.02). Moreover, the difference between the benefit coefficients in the two samples is statistically significant at the $10 \%$ level (t-ratio 1.98).

We also split the UI eligible sample into those with annual household income below and above $\$ 25,000$. Note, however, that it is unclear whether higher income households have greater ability to borrow. Chetty (2008) finds that higher income households are more likely to be paying off mortgages. Nevertheless, the unemployed with low annual household income are more responsive to benefits with an elasticity of -2.7 (t-ratio 1.78) compared to -0.8 (t-ratio 1.29) for those with household income higher than $\$ 25,000$, but the difference is not statistically significant at the $10 \%$ level.

Although not definitive, these results suggest that liquidity constraints have a potentially important impact on many job seekers, as the search intensity of those who have less access to financial resources appears to respond more strongly to UI benefits. To conduct a proper welfare analysis, however, we would like to estimate the elasticity of job search with respect to marginal increases in cash on hand, such as, for example, due 
to severance payments. Unfortunately, there is no such information currently available in the ATUS. Future research with time-use data might be able to distinguish the liquidity effect from the moral hazard effect.

\section{Summary and Conclusion}

This paper provides new evidence on job search intensity and Unemployment Insurance. We use data from the American Time Use Survey and model job search intensity as time allocated to job search activities, consistent with theoretical models. We find that time allocated to job search is inversely related to the maximum weekly benefit amount for UI eligible workers, with an elasticity of -1.6 to -2.2 , which is large enough to account for much of the gap in job search time between the U.S. and Europe. We also find that job search increases sharply in the weeks prior to benefit exhaustion, in line with Mortensen's (1977) model. These findings highlight the utility of simple search models for understanding job search behavior and UI.

A finding that is inconsistent with Mortensen's (1977) search model, however, is that search effort appears to decline after week 26, when benefits run out, rather than remain constant. This finding deserves further attention. One possible explanation is that the unemployed become discouraged if they fail to find a job despite substantially increasing their search effort before UI benefits run out at 26 weeks, and consequently stop searching. A related explanation is that the unemployed may feel that they have explored all of their plausible job opportunities after they sharply raised their search effort in the weeks leading up to the exhaustion of their UI benefits, and rationally feel they have little to gain from maintaining the same level of search effort over the next few months. 
Another finding is that each job seeker's fitted wage is a strong predictor of the amount of time he or she allocates to job search. Because we control for the same demographic variables in the search and wage equations, this finding suggests that wage premia associated with state of residence provide incentives for job search. Higher residual wage dispersion in a state, however, has an insignificant though usually positive association with job search in our base specification. It is unclear why we found that wage dispersion at the country level is significantly related to job search activity in Krueger and Mueller (2008) but is insignificant when cross-state variability is used for the U.S., although the lower wage dispersion across states than countries poses a greater challenge for estimation in the present paper. Lastly, we find that job seekers who likely have less access to financial resources (e.g., because they do not have a working spouse) tend to respond more to UI benefits than do those with greater financial wherewithal, consistent with a role for liquidity constraints.

Our findings suggest that time-use data offer a fruitful approach for research on job search intensity. In particular, if future ATUS surveys collect data on unemployment duration, one could further investigate the link between unemployment duration and job search, and test the predictions of other search models, e.g., stock-flow matching models, which predict a U-shaped unemployment duration-search profile. Longitudinal time-use data would help to control for length-based sampling and individual heterogeneity in job search activity. Moreover, data on severance payments and asset positions of the unemployed could allow one to determine the relative importance of moral hazard and liquidity effects of unemployment benefits. 


\section{References}

Alvarez, Fernando and Robert Shimer. 2008. "Search and Rest Unemployment." NBER Working Paper No. 13772, Cambridge, MA.

Card, David, Raj Chetty and Andrea Weber. 2007. "The Spike at Benefit Exhaustion: Leaving the Unemployment System or Starting a New Job?" American Economic Review: Papers and Proceedings 97 (2): 113-8.

Chetty, Raj. 2008. "Moral Hazard versus Liquidity and Optimal Unemployment Insurance.” Journal of Political Economy 116(2): 173-234.

Coles, Melvyn and Eric Smith. 1998. "Marketplaces and Matching." International Economic Review 39(1): 239-254.

Feldstein, Martin. 1976. "Temporary Layoffs in the Theory of Unemployment." The Journal of Political Economy 84(5): 937-957.

Feldstein, Martin and James Poterba. 1984. "Unemployment insurance and reservation wages." Journal of Public Economics 23(1-2): 141-67.

Flinn, Christopher and James Heckman. 1983. "Are unemployment and out of the labor force behaviorally distinct states?" Journal of Labor Economics 1(1): 28-42.

Gruber, Jonathan. 1994. "The Consumption Smoothing Benefits of Unemployment Insurance.” NBER Working Paper No. 4750, Cambridge, MA.

Holzer, Harry. 1987. "Job Search by Employed and Unemployed Youth." Industrial and Labor Relations Review 40(4): 601-611.

Jones, Stephen. 1988. "The Relationship Between Unemployment Spells and Reservation Wages as a Test of Search Theory." The Quarterly Journal of Economics 103 (4): 741-65.

Jones, Stephen and W. Craig Riddell. 1999. "The Measurement of Unemployment: An Empirical Approach.” Econometrica 67 (1): 147-61.

Katz, Lawrence. 1986. "Layoffs, Recall and the Duration of Unemployment". NBER Working Paper No. 1825, Cambridge, MA.

Katz, Lawrence and Bruce Meyer. 1990a. "The impact of the potential duration of unemployment benefits on the duration of unemployment." Journal of Public Economics 41(1): 45-72. 
Katz, Lawrence and Bruce Meyer. 1990b. "Unemployment Insurance, Recall Expectations, And Unemployment Outcomes." Quarterly Journal of Economics 105(4): 973-1002.

Krueger, Alan and Bruce Meyer. 2002. "Labor Supply Effects of Social Insurance.” In: Alan Auerbach and Martin Feldstein (editors), Handbook of Public Economics Vol 4. North-Holland: Amsterdam.

Krueger, Alan and Andreas Mueller. 2008. "The Lot of the Unemployed: A Time Use Perspective." IZA Discussion Paper No. 3490, Institute for the Study of Labor (IZA), Bonn, Germany.

Levine, Phillip. 1993. "Spillover Effects Between the Insured and Uninsured Unemployed." Industrial and Labor Relations Review, 47(1): 73-86.

Ljungqvist, Lars and Thomas Sargent. 1995. "Welfare States and Unemployment." Economic Theory 6(1): 143-160.

Ljungqvist, Lars and Thomas Sargent. 1998. "The European Unemployment Dilemma." The Journal of Political Economy 106(3): 514-550.

Moffitt, Robert. 1985. "Unemployment Insurance and the Distribution of Unemployment Spells.” Journal of Econometrics, 28(1): 85-101.

Mortensen, Dale. 1977. "Unemployment Insurance and Job Search Decisions." Industrial and Labor Relations Review 30(4): 505-517.

Paserman, Daniele. 2007. "Job Search and Hyperbolic Discounting: Structural Estimation and Policy Evaluation.” Forthcoming, Economic Journal.

Shimer, Robert. 2004. "Search Intensity." mimeo., University of Chicago, Chicago, IL.

Stigler, George. 1962. "Information in the Labor Market." Journal of Political Economy 70 (5), Part 2: 94-105. 
Appendix Table. Definition and examples of job search activities in ATUS 2006

Job search activities (050401), e.g.:

contacting employer

making phone calls to prospective employer

sending out resumes

asking former employers to provide references

auditioning for acting role (non-volunteer)

auditioning for band/symphony (non-volunteer)

placing/answering ads

researching details about a job

filling out job application

asking about job openings

reading ads in paper/on Internet

checking vacancies

researching an employer

submitting applications

writing/updating resume

meeting with headhunter/temp agency

picking up job application

Interviewing (050403), e.g.:

interviewing by phone or in person

scheduling/canceling interview (for self)

preparing for interview

Other activities related to job search, e.g.:

waiting associated with job search interview (050404)

security procedures rel. to job search/interviewing (050405)

travel related to job search (180504)

job search activities, not elsewhere specified (050499) 
Figure 1. Average number of minutes devoted to job search per day on weekdays by unemployed workers in various countries

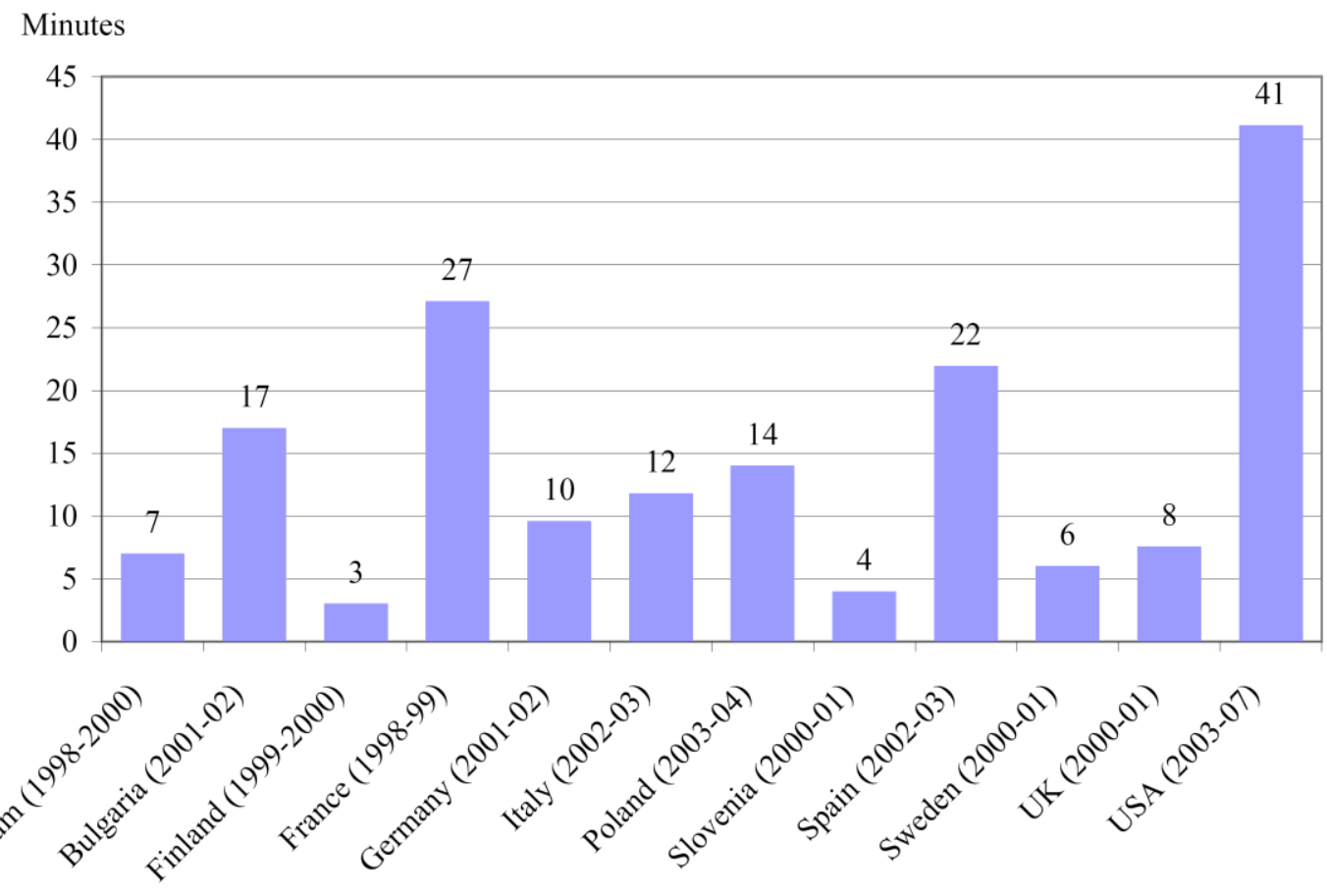

Notes: See Krueger and Mueller (2008) for details about the underlying time use data. 
Fig 2a. Search intensity and unemployment benefits

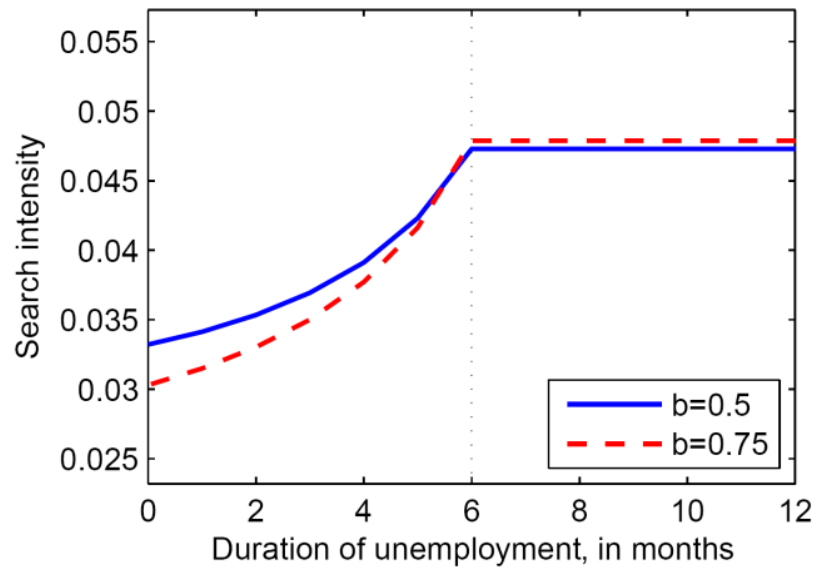

Fig 2c. Search intensity and the average log(wage)

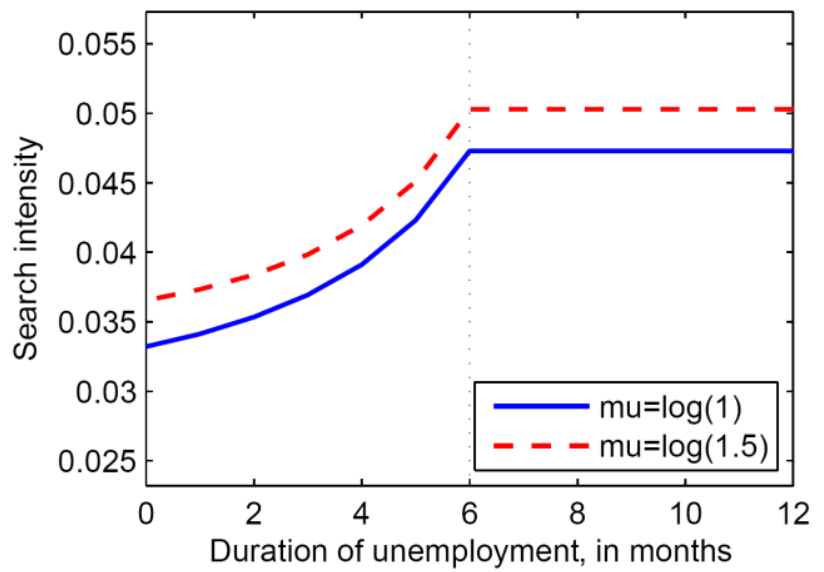

Fig 2 b. Search intensity and eligibility status

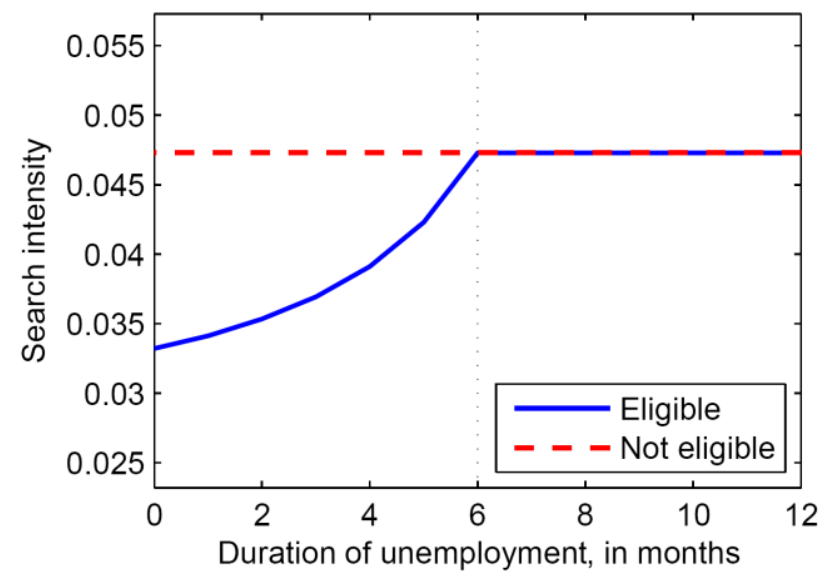

Fig 2d. Search intensity and wage dispersion

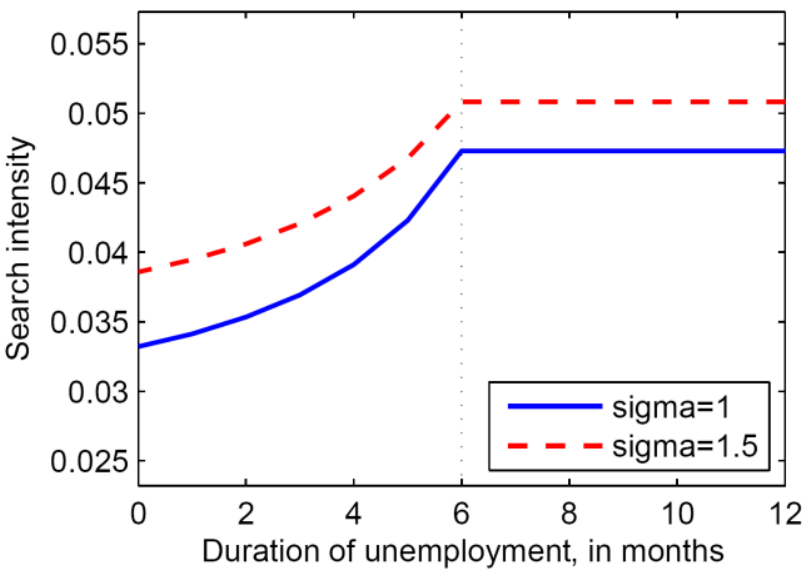

Notes: The model is solved numerically for the following parameter values: $\mathrm{h}=1$ month, $\mathrm{T}=6$ months, $\mathrm{r}=0.0041, \delta$ (job separation rate) $=0.05, \alpha=15, \gamma=1150, \mathrm{~b}=0.5, \mathrm{~b} 2$ (consumption of unemployed after benefit exhaustion) $=0.1 . \alpha$ is calibrated to match a monthly job offer rate of approximately 0.5 for a newly-laid off; $\gamma$ is calibrated such that time spent on job search matches time spent on job search in ATUS (as a fraction of total non-sleeping time available per week). 


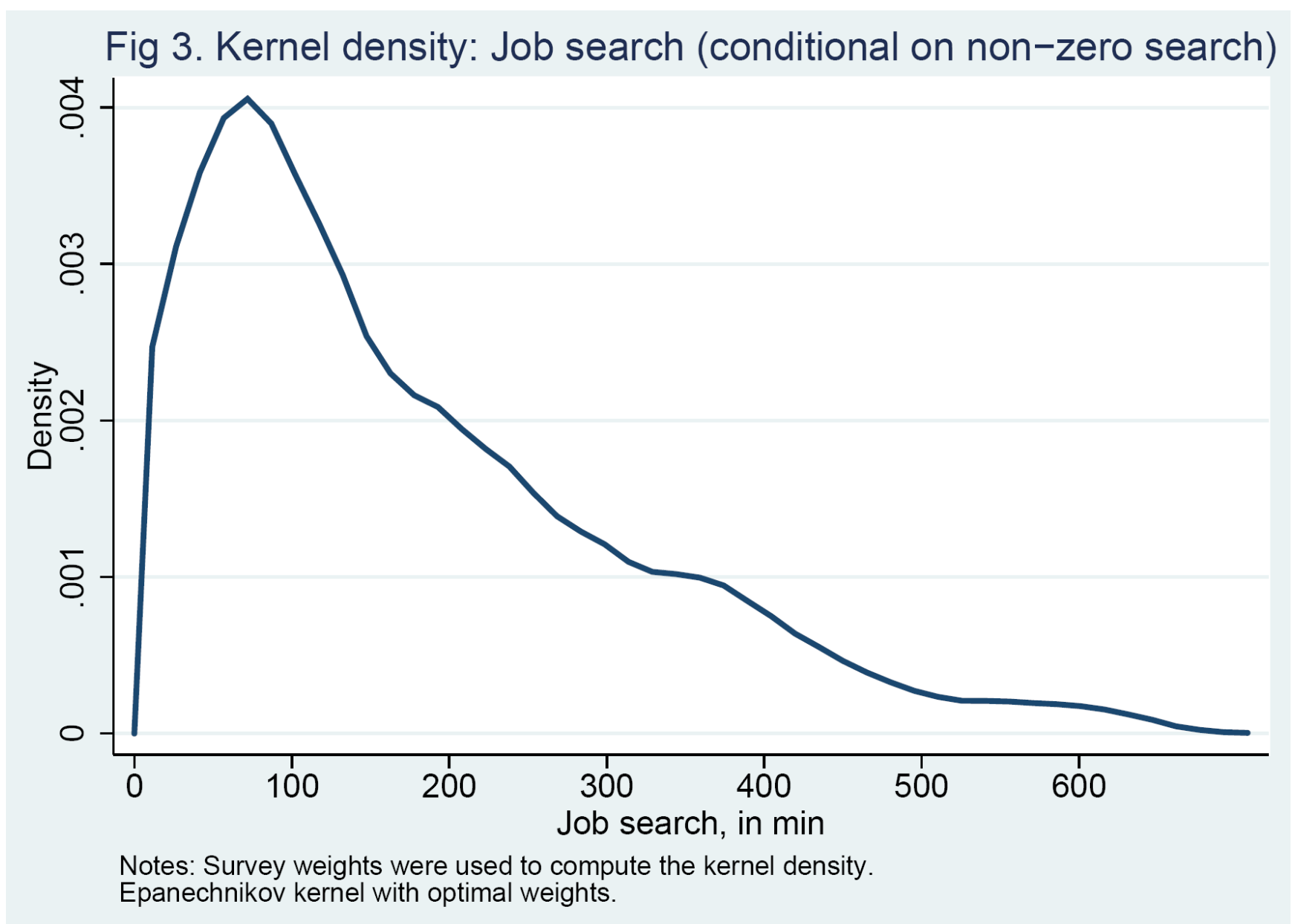


Fig 4. Lowess: job search by unemployment duration

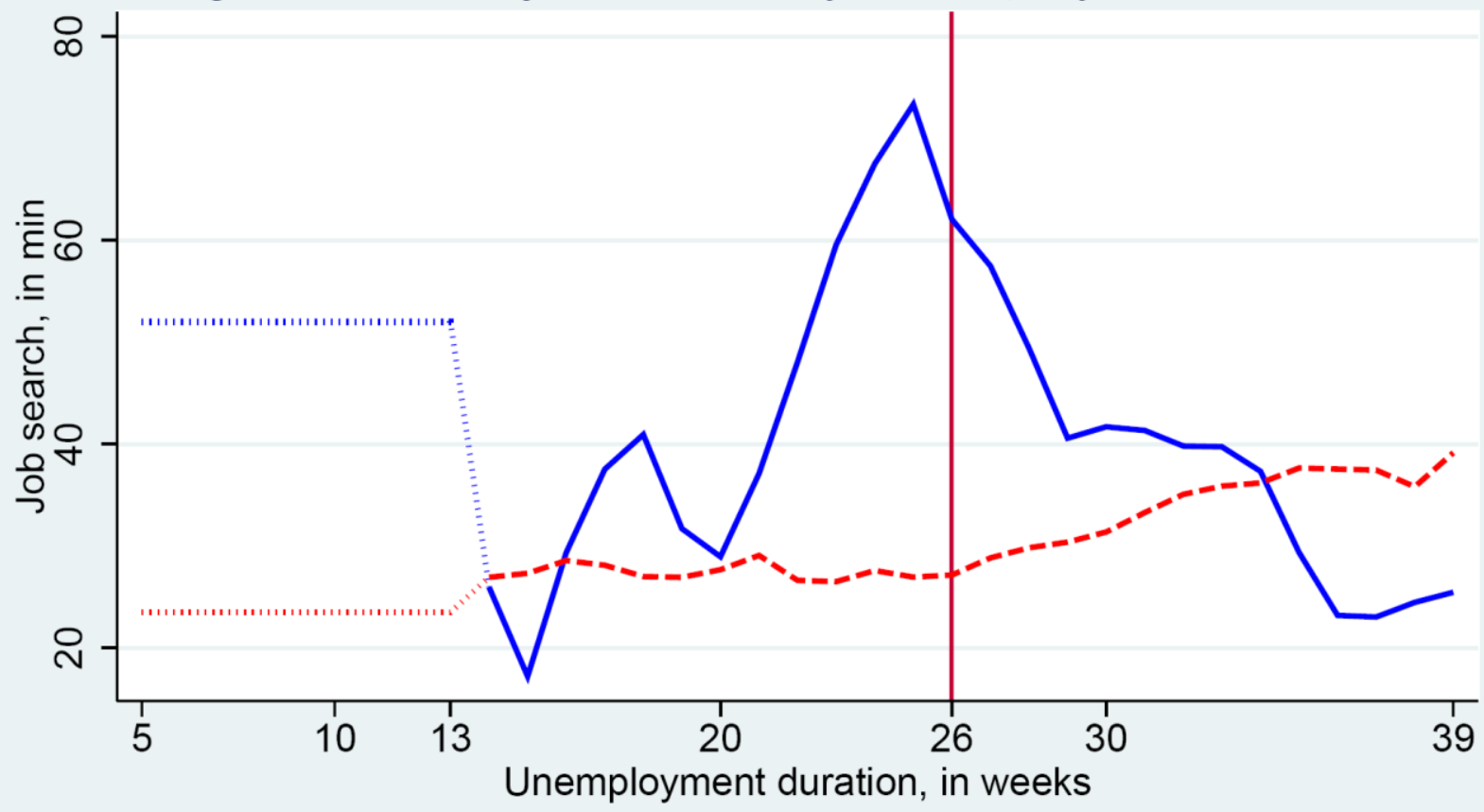

UI eligible ------- UI ineligible

Notes: Bandwidth $=0.1$. Survey weights are used to compute the lowess smoother.

Unemployed with an expectation of recall to their previous employer are excluded from the sample.

Fig 5. Lowess: job search by unemployment duration

Residuals from baseline regression model

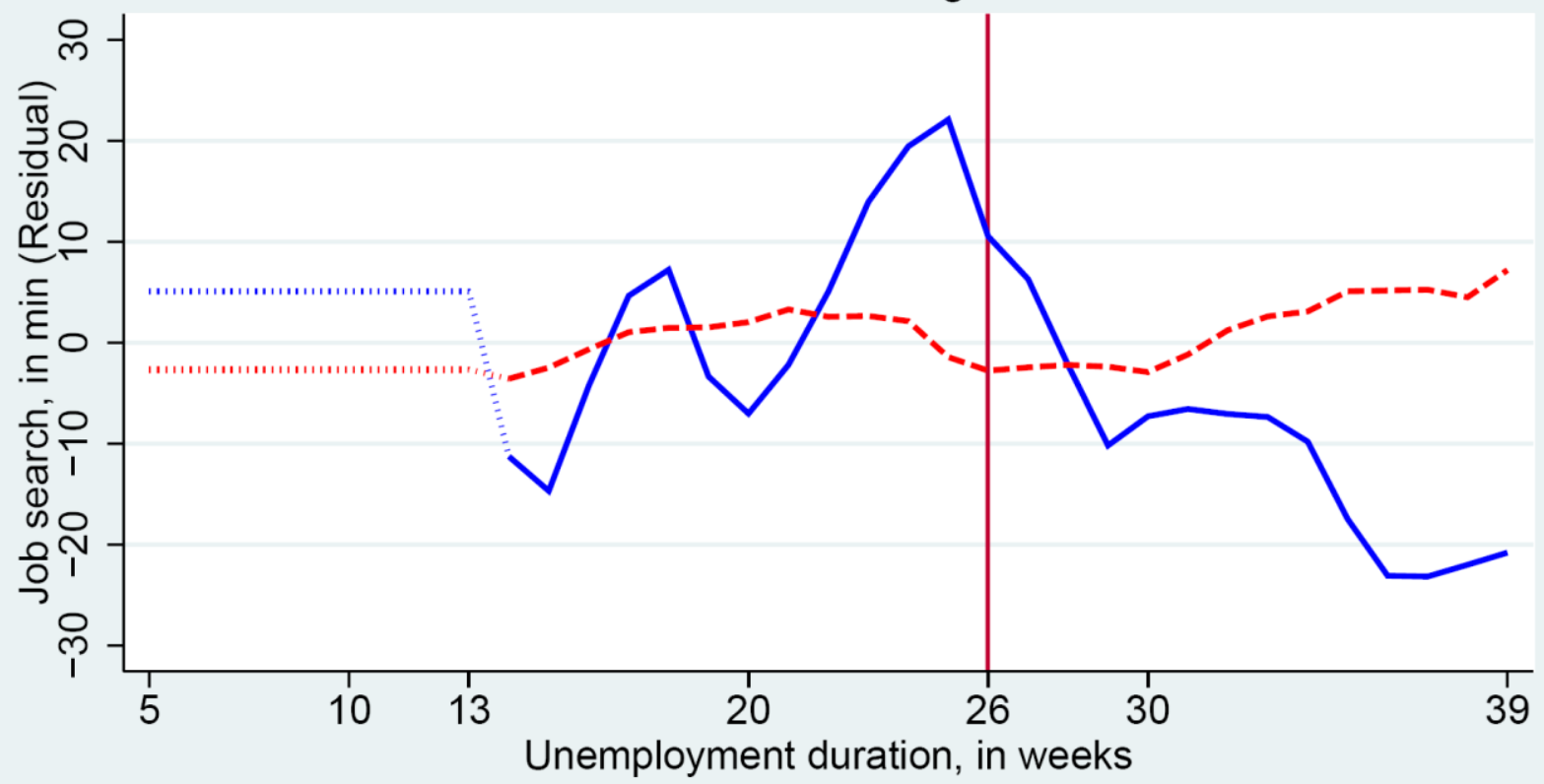

\section{Ul eligible}

\section{Ul ineligible}

Notes: Bandwidth $=0.1$. Survey weights are used to compute the lowess smoother.

Unemployed with an expectation of recall to their previous employer are excluded from the sample. 
Fig 6. Length based sampling:

Fraction of survivors by unemployment duration

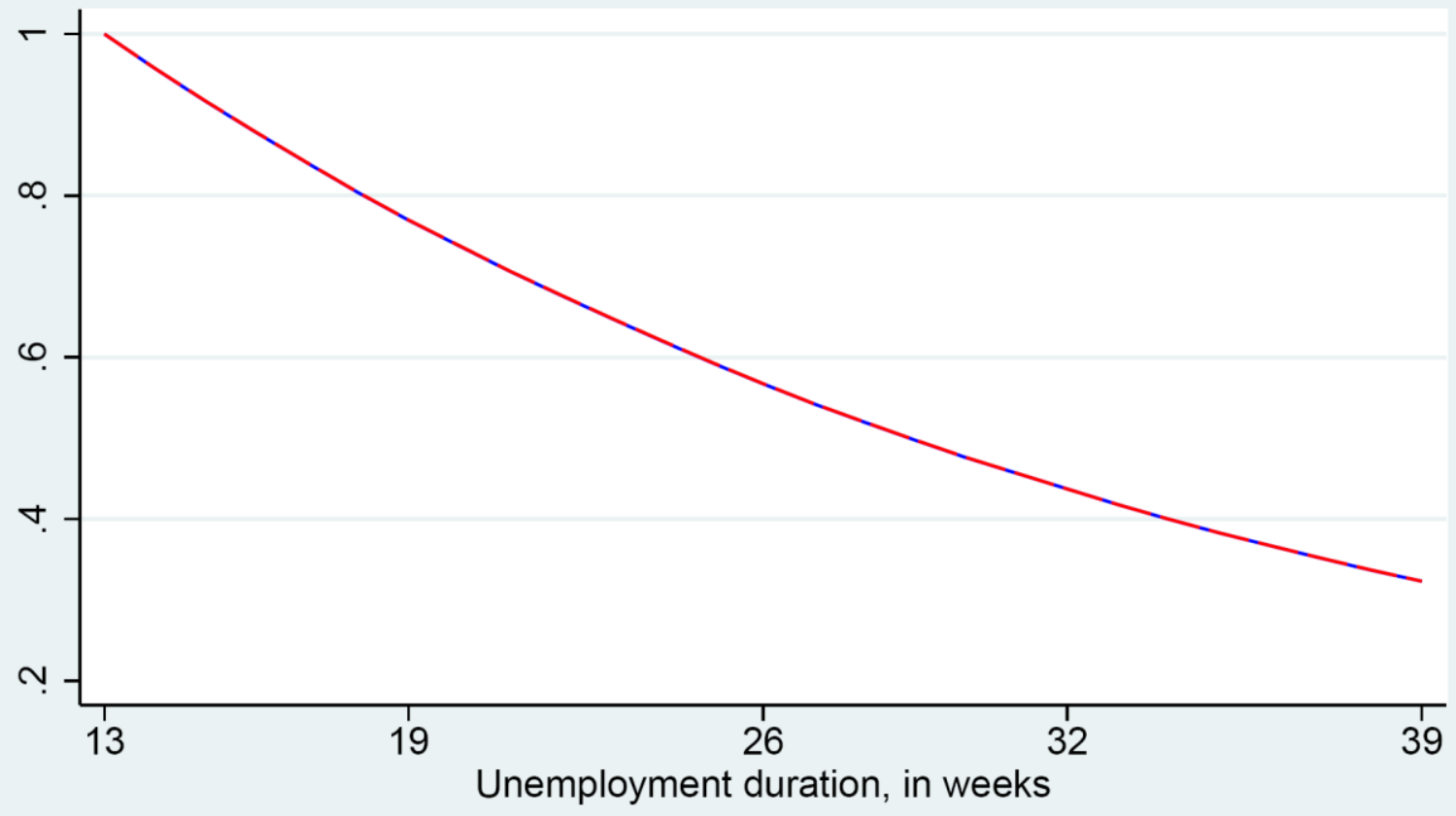

Fraction of survivors (IV) $\quad--$ Fraction of survivors (OLS)

Fig 7. Length based sampling:

Average search by unemployment duration

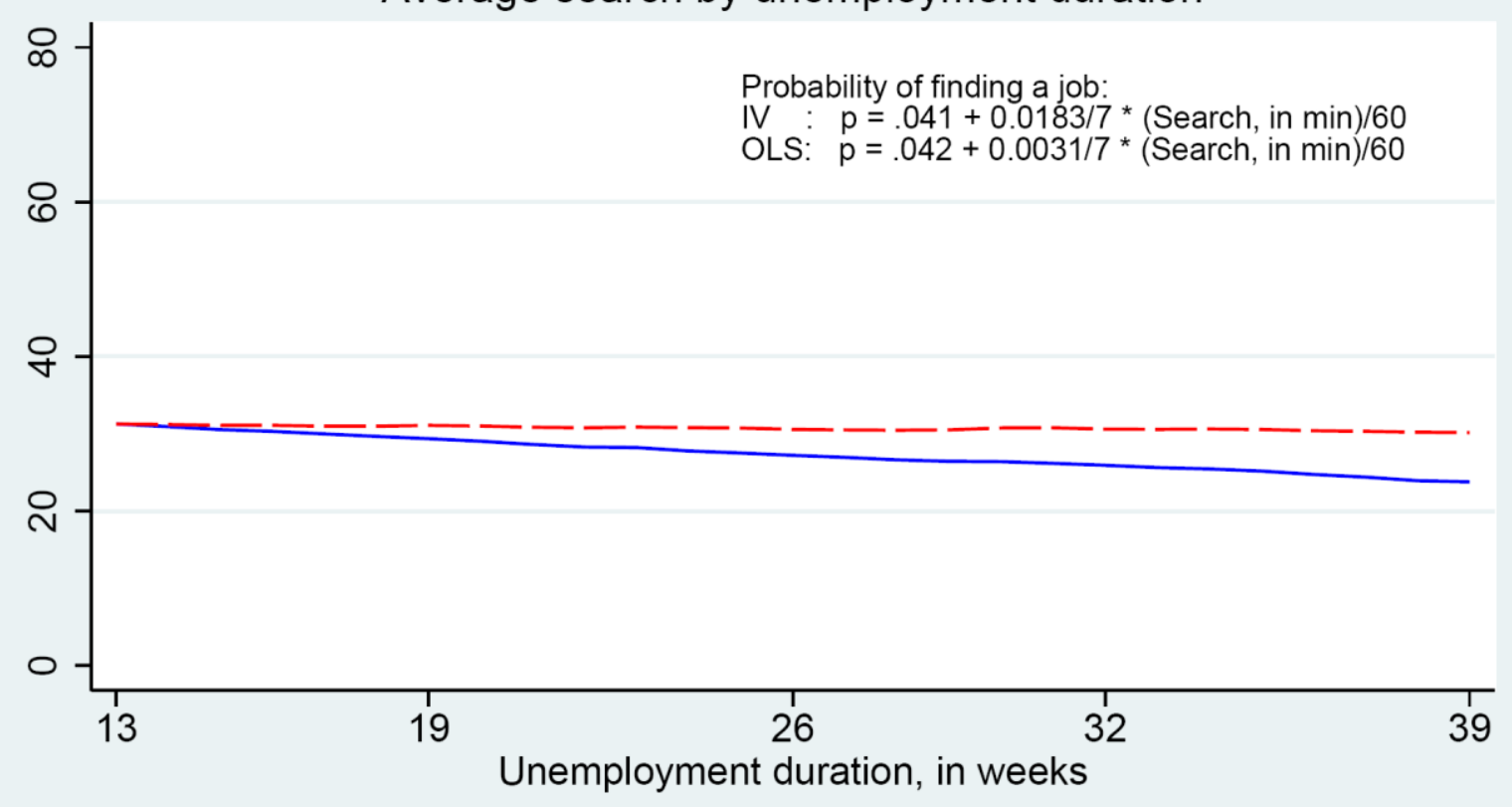

Average search, in min (IV) - - Average search, in min (OLS)

Survey weights are used to compute averages. 
Table 1a. Descriptive statistics ATUS 2003 - 2007, by labor force status

Average job

search

Average job Participation (participants), \# respondents \% of total search, in min in job search in $\min$

By labor force status

\begin{tabular}{lccccc}
\hline Employed & 42,934 & $76.4 \%$ & 0.6 & $0.6 \%$ & 101.0 \\
Unemployed & 2,171 & $3.9 \%$ & 32.1 & $19.3 \%$ & 166.9 \\
Not in labor force & 11,091 & $19.7 \%$ & 0.8 & $0.5 \%$ & 152.9 \\
\hline
\end{tabular}

By type of employed

(\% of employed)

\begin{tabular}{lccccc} 
Working in CPS & 40,576 & $94.5 \%$ & 0.5 & $0.5 \%$ & 107.6 \\
Unemployed in CPS & 824 & $1.9 \%$ & 2.8 & $2.5 \%$ & 115.4 \\
Not in labor force in CPS & 1,534 & $3.6 \%$ & 0.8 & $1.7 \%$ & 49.7 \\
\hline
\end{tabular}

By type of unemployed (\% of unemployed)

Jobloser 943

$43.4 \%$

45.2

$27.5 \%$

164.2

On temporary layoff $\mathrm{w} /$ recall expectation 344

$15.8 \%$

13.2

$7.1 \%$

185.8

Jobleaver

65

$3.0 \%$

52.9

$24.9 \%$

212.3

Re- or new entrant

819

$37.7 \%$

23.1

$14.1 \%$

163.6

By UI eligibility status

(\% of unemployed)

UI ineligible

1,000

$46.1 \%$

25.4

$15.6 \%$

163.4

UI eligible

1,171

$53.9 \%$

38.0

$22.5 \%$

169.1

By type of "not in labor force" (\% of not in labor force)

\begin{tabular}{lccccc} 
Working in CPS & 1,181 & $10.6 \%$ & 2.4 & $1.8 \%$ & 134.1 \\
Unemployed in CPS & 305 & $2.7 \%$ & 4.2 & $3.2 \%$ & 130.8 \\
Not in labor force in CPS & 9,605 & $86.6 \%$ & 0.5 & $0.3 \%$ & 176.7 \\
\hline
\end{tabular}

Notes: Averages and participation rates are computed with survey weights. Universe: Civilian, noninstitutional population, age 20-65. 
Table 1b. Descriptive statistics ATUS 2003 - 2007, by labor force status (weekdays only)

\# respondents $\quad \%$ of total $\begin{gathered}\text { Average job } \\
\text { search, in min }\end{gathered} \quad \begin{aligned} & \text { Participation } \\
& \text { in job search }\end{aligned} \quad$\begin{tabular}{c}
$\begin{array}{c}\text { Average job } \\
\text { search } \\
\text { (participants), } \\
\text { in min }\end{array}$ \\
\hline
\end{tabular}

\section{By labor force status}

\begin{tabular}{lccccc}
\hline Employed & 21,291 & $76.4 \%$ & 0.7 & $0.7 \%$ & 99.7 \\
Unemployed & 1,076 & $3.9 \%$ & 41.1 & $24.1 \%$ & 170.8 \\
Not in labor force & 5,495 & $19.7 \%$ & 1.1 & $0.7 \%$ & 159.8 \\
\hline
\end{tabular}

By type of employed

(\% of employed)

\begin{tabular}{lccccc}
\hline Working in CPS & 20,141 & $94.6 \%$ & 0.6 & $0.6 \%$ & 106.0 \\
Unemployed in CPS & 395 & $1.9 \%$ & 3.7 & $3.0 \%$ & 123.3 \\
Not in labor force in CPS & 755 & $3.5 \%$ & 0.8 & $1.9 \%$ & 40.8 \\
\hline
\end{tabular}

By type of unemployed

(\% of unemployed)

Jobloser
On temporary layoff

$\mathrm{w} /$ recall expectation

488

$45.4 \%$

56.2

$33.6 \%$

167.0

171

$15.9 \%$

16.7

$8.9 \%$

188.9

Jobleaver

25

$2.3 \%$

69.6

$33.7 \%$

206.4

Re- or new entrant

392

$36.4 \%$

30.5

$17.8 \%$

171.3

By UI eligibility status

(\% of unemployed)

\begin{tabular}{llllll}
\hline UI ineligible & 473 & $44.0 \%$ & 33.2 & $19.6 \%$ & 169.5 \\
UI eligible & 603 & $56.0 \%$ & 47.9 & $27.9 \%$ & 171.5 \\
\hline
\end{tabular}

By type of "not in labor force"

(\% of not in labor force)

\begin{tabular}{lccccc}
\hline Working in CPS & 572 & $10.4 \%$ & 3.5 & $2.4 \%$ & 143.6 \\
Unemployed in CPS & 159 & $2.9 \%$ & 5.6 & $4.1 \%$ & 136.6 \\
Not in labor force in CPS & 4,764 & $86.7 \%$ & 0.7 & $0.4 \%$ & 181.4 \\
\hline
\end{tabular}

Notes: Averages and participation rates are computed with survey weights. Universe: Civilian, noninstitutional population, age 20-65. 


\section{Table 2. Results of linear regressions for job search time}

\section{Dependent variable: time allocated to job} search, in min
Mean (Std)
Full sample (1)
Subsample (2): eligible /o recall expectation \& udur $<=26$
Subsample (3): ineligible
Subsample (4):
ineligible \&

ineligible \&

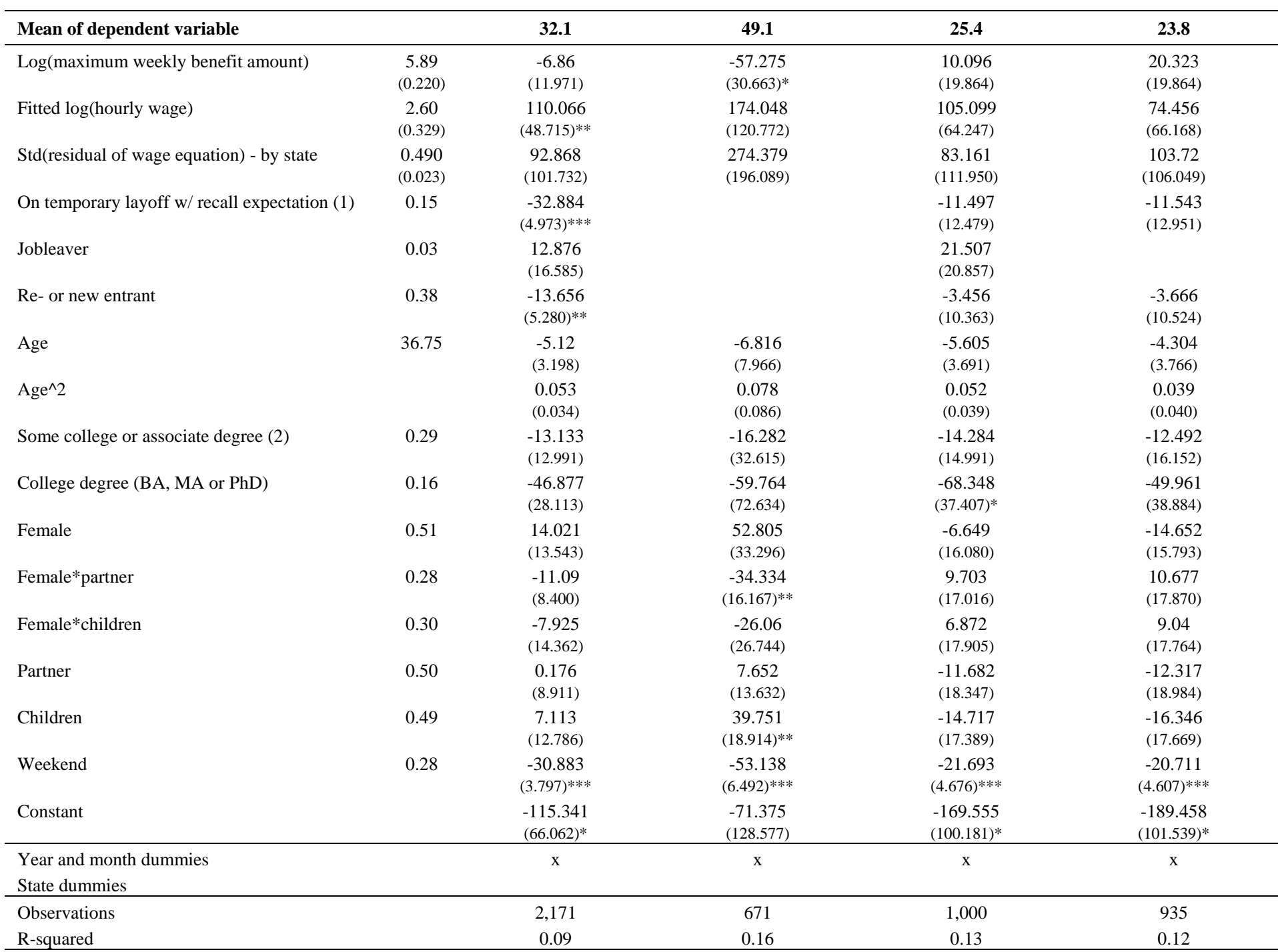

Robust standard errors in parentheses

* significant at $10 \%$; ** significant at $5 \%$; *** significant at $1 \%$

Notes: Regressions are weighted using survey weights; Errors are clustered at state level. Universe: Unemployed, age 20-65. Source for wage equation: CPS outgoing rotation group extract, 2004 and 2005. The CEPR version of the ORG contains hourly wage series that adjust for topcoding and overtime earnings/tips. We exclude from the sample self-employed and self-incorporated, full-time and part-time students and employed with hourly earnings of less than $\$ 1$ or more than $\$ 200$.

(1) The base group consists of Job losers. (2) The base group consists of those with a high school degree or less.

Wage equation dependent variable: $\log ($ hourly wage)

\begin{tabular}{c}
$\mathrm{x}$ \\
\hline 319,813 \\
0.29 \\
\hline
\end{tabular}


Dependent variable: time allocated to job search, in min

\begin{tabular}{|c|c|c|c|c|c|}
\hline $\begin{array}{l}\text { Dependent variable: time allocated to job } \\
\text { search, in min }\end{array}$ & $\underset{\text { (Std) }}{\text { Mean }}$ & Full sample (1) & $\begin{array}{c}\text { Subsample (2): eligible } \\
\text { w/o recall expectation } \\
\& \text { udur }<=26\end{array}$ & $\begin{array}{l}\text { Subsample (3): } \\
\text { ineligible }\end{array}$ & $\begin{array}{c}\text { Subsample (4): } \\
\text { ineligible \& } \\
\text { not jobleaver }\end{array}$ \\
\hline Mean of dependent variable & & 32.1 & 49.1 & 25.4 & 23.8 \\
\hline Adjustment factor for marginal effects & & 0.153 & 0.256 & 0.115 & 0.110 \\
\hline $\log ($ maximum weekly benefit amount) & $\begin{array}{c}5.89 \\
(0.220)\end{array}$ & $\begin{array}{l}24.344 \\
(46.807)\end{array}$ & $\begin{array}{c}-156.8 \\
(78.173)^{* *}\end{array}$ & $\begin{array}{l}117.917 \\
(110.082)\end{array}$ & $\begin{array}{l}169.395 \\
(116.734)\end{array}$ \\
\hline Fitted $\log$ (hourly wage) & $\begin{array}{c}2.60 \\
(0.329)\end{array}$ & $\begin{array}{c}548.212 \\
(205.572)^{* * * *}\end{array}$ & $\begin{array}{c}652.484 \\
(315.049)^{* *}\end{array}$ & $\begin{array}{c}801.735 \\
(334.230)^{* *}\end{array}$ & $\begin{array}{c}782.099 \\
(354.620)^{* *}\end{array}$ \\
\hline $\operatorname{Std}($ residual of wage equation) - by state & $\begin{array}{c}0.49 \\
(0.023)\end{array}$ & $\begin{array}{l}-12.808 \\
(572.653)\end{array}$ & $\begin{array}{l}380.496 \\
(648.979)\end{array}$ & $\begin{array}{l}-456.146 \\
(709.477)\end{array}$ & $\begin{array}{l}-455.813 \\
(703.195)\end{array}$ \\
\hline On temporary layoff $w /$ recall expectation (1) & 0.15 & $\begin{array}{l}-239.506 \\
(38.298)^{* * *}\end{array}$ & & (2) & (2) \\
\hline Jobleaver & 0.03 & $\begin{array}{l}10.194 \\
(58.054)\end{array}$ & & $\begin{array}{l}98.642 \\
(88.601)\end{array}$ & \\
\hline Re- or new entrant & 0.38 & $\begin{array}{c}-80.834 \\
(24.674)^{* * *}\end{array}$ & & $\begin{array}{l}12.685 \\
(47.770)\end{array}$ & $\begin{array}{c}16.68 \\
(48.193)\end{array}$ \\
\hline Age & 36.75 & $\begin{array}{l}-24.237 \\
(15.895)\end{array}$ & $\begin{array}{l}-25.049 \\
(23.579)\end{array}$ & $\begin{array}{c}-44.41 \\
(20.642)^{* *}\end{array}$ & $\begin{array}{c}-45.673 \\
(21.920)^{* *}\end{array}$ \\
\hline $\mathrm{Age}^{\wedge} 2$ & & $\begin{array}{c}0.245 \\
(0.173)\end{array}$ & $\begin{array}{l}0.271 \\
(0.259)\end{array}$ & $\begin{array}{c}0.421 \\
(0.216)^{*}\end{array}$ & $\begin{array}{c}0.436 \\
(0.229)^{*}\end{array}$ \\
\hline Some college or associate degree (3) & 0.29 & $\begin{array}{l}-53.855 \\
(53.329)\end{array}$ & $\begin{array}{l}-77.851 \\
(88.886)\end{array}$ & $\begin{array}{l}-119.538 \\
(82.067)\end{array}$ & $\begin{array}{l}-128.672 \\
(87.423)\end{array}$ \\
\hline College degree (BA, MA or PhD) & 0.16 & $\begin{array}{c}-241.132 \\
(113.629)^{* *}\end{array}$ & $\begin{array}{r}-269.902 \\
(188.471)\end{array}$ & $\begin{array}{c}-437.329 \\
(189.517)^{* *}\end{array}$ & $\begin{array}{c}-420.545 \\
(205.614)^{* *}\end{array}$ \\
\hline Female & 0.51 & $\begin{array}{l}87.409 \\
(57.036)\end{array}$ & $\begin{array}{c}201.337 \\
(95.916)^{* *}\end{array}$ & $\begin{array}{l}75.857 \\
(77.953)\end{array}$ & $\begin{array}{c}65.972 \\
(79.252)\end{array}$ \\
\hline Female*partner & 0.28 & $\begin{array}{l}-66.344 \\
(42.073)\end{array}$ & $\begin{array}{c}-88.332 \\
(52.342)^{*}\end{array}$ & $\begin{array}{l}-34.636 \\
(73.483)\end{array}$ & $\begin{array}{l}-25.595 \\
(79.928)\end{array}$ \\
\hline Female*children & 0.30 & $\begin{array}{l}-38.338 \\
(59.715)\end{array}$ & $\begin{array}{c}-111.368 \\
(81.905)\end{array}$ & $\begin{array}{l}30.277 \\
(69.874)\end{array}$ & $\begin{array}{c}34.403 \\
(70.669)\end{array}$ \\
\hline Partner & 0.50 & $\begin{array}{c}-4.038 \\
(37.283)\end{array}$ & $\begin{array}{c}0.006 \\
(46.859)\end{array}$ & $\begin{array}{l}-14.787 \\
(66.825)\end{array}$ & $\begin{array}{l}-20.759 \\
(70.715)\end{array}$ \\
\hline Children & 0.49 & $\begin{array}{l}12.663 \\
(40.987)\end{array}$ & $\begin{array}{c}120.419 \\
(52.645)^{* *}\end{array}$ & $\begin{array}{l}-93.485 \\
(60.902)\end{array}$ & $\begin{array}{l}-96.002 \\
(63.550)\end{array}$ \\
\hline Weekend & 0.28 & $\begin{array}{c}-218.167 \\
(20.653)^{* * *}\end{array}$ & $\begin{array}{c}-223.945 \\
(25.780)^{* * *}\end{array}$ & $\begin{array}{c}-175.855 \\
(31.905)^{* * *}\end{array}$ & $\begin{array}{c}-172.081 \\
(31.877)^{* * *}\end{array}$ \\
\hline Constant & & $\begin{array}{c}-1062.408 \\
(332.084)^{* * * *}\end{array}$ & $\begin{array}{r}-530.797 \\
(503.571) \\
\end{array}$ & $\begin{array}{c}-1590.845 \\
(574.960) * * *\end{array}$ & $\begin{array}{c}-1816.338 \\
(615.295)^{* * *}\end{array}$ \\
\hline sigma & & $\begin{array}{c}264.087 \\
(15.127)^{* * *}\end{array}$ & $\begin{array}{c}230.892 \\
(11.709)^{* * *}\end{array}$ & $\begin{array}{c}261.18 \\
(26.881)^{* * *}\end{array}$ & $\begin{array}{c}260.104 \\
(31.760)^{* * * *}\end{array}$ \\
\hline Year and month dummies & & $\mathrm{x}$ & $\mathrm{x}$ & $\mathrm{x}$ & $\mathrm{x}$ \\
\hline Observations & & 2,171 & 671 & 1,000 & 935 \\
\hline Pseudo R-squared & & 0.04 & 0.04 & 0.06 & 0.05 \\
\hline
\end{tabular}

Robust standard errors in parentheses; * significant at 10\%; ** significant at 5\%; *** significant at $1 \%$

Notes: Regressions are weighted using survey weights; Errors are clustered at state level. Universe: Unemployed, age 20-65. Source for wage equation: same as in Table 2.

(1) The base group consists of Job losers. (2) We exclude the dummy for temporary layoff w/ expectation of recall for this regression, because there are only 27 of them in the sample of ineligible (part-time workers in states were part-time workers are not eligible for UI) and they all have zero search on the diary day. (3) The base group consists of those with a high school degree or less. 
Table 4. Instrumental variables (IV) regressions, marginal effect of $\log$ (average weekly benefit)

\section{Dependent variable: time allocated to job search, in min}

Subsample (2): eligible w/o recall expectation \& udur $<=26$

\section{Subsample (3):} ineligible
Subsample (4): ineligible \& not jobleaver

\section{Mean of dependent variable}

32.1

49.1

25.4

23.8

OLS

Log(state average weekly benefit)

$\begin{array}{lc}12.564 & -99.696 \\ (16.562) & (42.273)^{* *}\end{array}$

50.649

59.639

(16.562)

$(42.273)^{* *}$

$(24.731)^{* *}$

$(25.850)^{* *}$

IV - 2SLS (Instrument: $\log ($ maximum weekly benefit amount))

\begin{tabular}{lllll}
\hline $\log ($ state average weekly benefit) & -12.612 & -109.74 & 18.109 & 36.255 \\
& $(22.504)$ & $(58.433)^{*}$ & $(35.004)$ & $(34.378)$
\end{tabular}

Tobit

$\log ($ state average weekly benefit)

20.458

$-71.004$

$(34.473)^{* *}$

41.583

$(18.008)^{* * *}$

47.419

$(18.479)^{* * *}$

IV - Tobit (Instrument: $\log ($ maximum weekly benefit amount))

\begin{tabular}{lcccc}
\hline Log(state average weekly benefit) & $\begin{array}{c}7.909 \\
(13.126)\end{array}$ & $\begin{array}{c}-77.511 \\
(39.489)^{* *}\end{array}$ & 28.312 & 37.531 \\
& & & $(22.004)$ & $(23.097)$ \\
\hline Observations & 2,171 & 671 & 1,000 & 935 \\
\hline
\end{tabular}

Robust standard errors in parentheses

* significant at $10 \%$;* significant at $5 \%$; *** significant at $1 \%$

Notes: Regressions are weighted using survey weights; Errors are clustered at state level. Universe: Unemployed, age 20-65. The average weekly benefit is defined as benefits paid for total unemployment divided by weeks compensated for total unemployment. 
Table 5. Linear probability model of job finding

\begin{tabular}{|c|c|c|c|c|}
\hline Dependent variable: & $\begin{array}{c}\text { Mean } \\
(\text { Std })\end{array}$ & Job accepted & $\begin{array}{c}\text { 2SLS: 2nd stage } \\
\text { Job accepted }\end{array}$ & $\begin{array}{l}\text { 2SLS: 1st stage } \\
\text { Job search, in hrs }\end{array}$ \\
\hline Mean of dependent variable & & 0.16 & 0.16 & 3.97 \\
\hline Job search, in hrs & $\begin{array}{l}3.97 \\
(8.49)\end{array}$ & $\begin{array}{c}0.0031 \\
(0.0019)^{*}\end{array}$ & $\begin{array}{c}0.0183 \\
(0.0066)^{* * *}\end{array}$ & \\
\hline \# of jobsearch methods used & $\begin{array}{l}3.33 \\
(1.63)\end{array}$ & & & $\begin{array}{c}1.556 \\
(0.2786)^{* * *}\end{array}$ \\
\hline Female & 0.44 & $\begin{array}{l}-0.020 \\
(0.0290)\end{array}$ & $\begin{array}{c}0.006 \\
(0.0321)\end{array}$ & $\begin{array}{c}-1.225 \\
(0.5296)^{* *}\end{array}$ \\
\hline Age & $\begin{array}{l}20.20 \\
(1.82)\end{array}$ & $\begin{array}{c}0.000 \\
(0.0092)\end{array}$ & $\begin{array}{l}-0.002 \\
(0.0095)\end{array}$ & $\begin{array}{c}0.009 \\
(0.1523)\end{array}$ \\
\hline Years of school & $\begin{array}{l}11.67 \\
(1.60)\end{array}$ & $\begin{array}{c}0.019 \\
(0.0100)^{*}\end{array}$ & $\begin{array}{c}0.022 \\
(0.0107)^{* *}\end{array}$ & $\begin{array}{l}-0.197 \\
(0.1447)\end{array}$ \\
\hline Constant & & $\begin{array}{l}-0.013 \\
(0.2229)\end{array}$ & $\begin{array}{c}0.780 \\
(0.2146)^{* * * *}\end{array}$ & $\begin{array}{c}5.609 \\
(4.2748)\end{array}$ \\
\hline Month dummies & & $\mathrm{x}$ & $\mathrm{x}$ & $\mathrm{x}$ \\
\hline Observations & & 1,162 & 1,162 & 1,162 \\
\hline R-squared & & 0.02 & & 0.12 \\
\hline
\end{tabular}

Robust standard errors in parentheses

$*$ significant at $10 \%$; ** significant at $5 \%$; *** significant at $1 \%$

Notes: Survey weights are used for the estimates. Universe: Unemployed, age 18-24.

Source: Authors' calculations and National Longitudinal Survey of Youth 1979 (NLSY79), 1981. 